\title{
The Role of Self-Efficacy and Identity in Mediating the Effects of STEM Support Experiences
}

\author{
Moin Syed ${ }^{1}$, Eileen L. Zurbriggen², Martin M. Chemers², Barbara K. Goza², Steve Bearman², \\ Faye J. Crosby ${ }^{2}$, Jerome M. Shaw ${ }^{3}$, Lisa Hunter ${ }^{4}$ and Elizabeth M. Morgan²
}

Tentatively Accepted for Publication, Analyses of Social Issues and Public Policy Version: October 10, 2018

\begin{abstract}
Author Note
${ }^{1}$ Department of Psychology, University of Minnesota; ${ }^{2}$ Department of Psychology, University of California Santa Cruz; ${ }^{3}$ Department of Education, University of California Santa Cruz; ${ }^{4}$ Center for Adaptive Optics, University of California Santa Cruz.

This research was supported by Grant Number R01GM071935 from the National Institute Of General Medical Sciences. The content is solely the responsibility of the authors and does not necessarily represent the official views of the National Institute Of General Medical Sciences, or the National Institutes of Health. We are grateful for the support of our research team members; Julian Fernald and Sirinda Sincharoen from UCSC Institutional Research; and the participating faculty, staff, and students. Study materials and analytic code are available at https://osf.io/9y6j7/. The data reported in this article are not openly available, but are available from the authors upon request.
\end{abstract}

Correspondence concerning this article should be addressed to Moin Syed, Department of Psychology, University of Minnesota, 75 East River Road, Minneapolis, MN 55455, 612-6264206, moin@umn.edu. 


\begin{abstract}
We report results from two studies testing the Mediation Model of Research Experiences (MMRE), which posits that science (or engineering) self-efficacy and identity as a scientist (or engineer) mediate the association between support programs and students' commitment to science, technology, engineering, and mathematics (STEM) careers. Study 1 included 502 matriculated and recently graduated undergraduate STEM students. Structural equation modeling analyses indicated that research experience, instrumental mentoring, and involvement in a community of scientists were associated with commitment to a STEM career, mediated through science/engineering self-efficacy and identity as a scientist/engineer. There were few interactions with ethnicity and none with gender. In Study 2, 63 undergraduate students in science/engineering support programs were surveyed with a similar instrument at the beginning and end of their programs. Pre-post analyses indicated that increases over time in community involvement were associated with increases in science/engineering self-efficacy, and increases over time in science/engineering identity were associated with increased commitment to a STEM career. Taken together, these two studies show the importance of psychological processes such as identity and self-efficacy in understanding the specific ways in which science/engineering support programs lead to enhanced commitment to a career in STEM among white and underrepresented minority undergraduate students.
\end{abstract}

Keywords: Science self-efficacy, identity as a scientist, underrepresented minority students, science support programs, research experiences, internships, mentoring 


\section{The Role of Self-Efficacy and Identity in Mediating the Effects of STEM Support Experiences}

College students' selection of and persistence in science, technology, engineering, and mathematics (STEM) fields has been an ongoing social problem (Syed \& Chemers, 2011; Hrabowski, 2018). Equally of concern is the fact that ethnic minorities and women are substantially underrepresented in many STEM fields (Cheryan, Ziegler, Montoya, \& Jiang, 2017; Higher Education Research Institute, 2010; Hrabowksi, 2018; Rochin \& Mello, 2007). The research and educational communities have been very aware of the problem and have devoted considerable resources to develop solutions. The purpose of the present studies is to develop a deeper understanding of the psychological processes that may help explain the effectiveness of STEM support activities among ethnically-diverse college students. We do this by testing the empirical basis of a conceptual model, the Mediation Model of Research Experience (MMRE, Figure 1; Chemers, Zurbriggen, Syed, Goza, \& Bearman, 2011; Robnett, Chemers, \& Zurbriggen, 2015). In Study 1, we examine how psychological factors, specifically self-efficacy and identity, mediate the association between STEM support activities and commitment to a career in STEM. In Study 2, we examine how the STEM support activities, psychological factors, and commitment to a STEM career change over time in the context of program participation. Across both studies, we explore potential variations in the models by ethnicity and gender.

\section{Identifying the Active Ingredients: A Mediation Model of Research Experiences}

It is widely recognized that comprehensive solutions must address multiple levels of

analysis, covering institutional structures, relational factors, and individual differences (Syed, Azmitia, \& Cooper, 2011). In other words, targeting any one level of analysis is likely to be 
insufficient, and yet focused efforts must be made at each level. STEM support programs are widely implemented solutions that primarily focus on individual differences. Gándara and Maxwell-Jolly (1999) reported that the federal government had invested \$1.5 billion in programs to increase the number of minorities in science during the 1970s and 1980s. Despite results showing that some programs have been effective in helping some students (e.g., Meyerhoff Scholars Program; Maton et al., 2016; and the Biology Undergraduate Scholars Program at University of California, Jones, Barlow \& Villarejo, 2010), an empirical basis for a nuanced understanding about how and why programs are effective has been lacking (Syed \& Chemers, 2011). The paucity of targeted theory and empirically established findings leaves new programs and programs seeking to improve with only intuitive and anecdotal guides, and unable to translate success into practical implications that can be used to influence changes at an institutional level. That is, an understanding of STEM experiences that lead to increased commitment to a STEM career can inform the design of many teaching and learning contexts, including how science is taught in formal courses. Accordingly, there continues to be a need for research examining how and why STEM support activities might translate into a commitment to pursue a STEM-related career.

To address these needs and limitations, we developed a theoretical model, the Mediation Model of Research Experience (Figure 1; Chemers et al., 2011). The model was developed to help isolate and understand the processes that contribute to students' commitment to a research career and develop the capacities to persevere towards that goal. In this model, we hypothesize that the psychological variables of science self-efficacy, leadership and teamwork self-efficacy, and identity as a scientist mediate the effects of STEM support activities on outcomes such as 
commitment to a science career ${ }^{1}$. Further, we hypothesize that this mediation may be moderated by ethnicity and gender. Below we discuss each of the model components, in turn.

\section{STEM Support Activities}

Gándara and Maxwell-Jolly (1999) conducted an extensive review of STEM support programs for undergraduates and classified activities included in programs into five categories: research experience, mentoring, psychosocial support, academic support, and financial support. These same activities are also available to students not in support programs through less formal vehicles such as an opportunity to work in a professor's lab or act as a teaching assistant. These five categories of support are ostensibly the primary factors that contribute to success and persistence in STEM fields in the context of STEM support programs. And yet, we do not have sufficient data on how these support activities function; that is, what are the psychological mediators that help translate specific activities into an intention to pursue a STEM career? Moreover, despite their prevalence, few empirical examinations test the influence of all five activities simultaneously (but see Chemers et al., 2011).

Research experiences. One of the support experiences empirically identified as effective in supporting science students is the opportunity for students to experience "real” science or engineering through a research apprenticeship. A synthesis of 53 studies of research apprenticeships (Sadler, Burgin, McKinney, \& Punjuan, 2010) found that research experiences enhance science-related attitudes. In addition, students who were engaged in more complex aspects of research such as analysis, showed gains in scientific reasoning (e.g., Charney et al.,

\footnotetext{
${ }^{1}$ Although our sample included engineering students, the majority of participants were science students. Accordingly, although we will occasionally refer to "science/engineering self-efficacy" or "identity as a scientist/engineer" for brevity we will usually use the terms "science self-efficacy" and "identity as a scientist". These should be understood as encompassing engineering students. We will also use the term "STEM" interchangeably with "science/engineering" because there are relatively few mathematics majors (compared to science and engineering) and because in higher education technology is encompassed by engineering.
} 
2007; Ryder \& Leach, 1999). Apprenticeships affect the knowledge and skills of science learners at the high school and undergraduate levels (Bell, Blair, Crawford, \& Lederman, 2003; Budassi \& Rafailovich, 2018; McDevitt, Patel, Rose, \& Ellison, 2016). Students identify many benefits of their undergraduate research, including increased confidence and science skills (Seymour, Hunter, Laursen, \& Deantoni, 2004) as well as experiences with the culture of science (Chang, Sharkness, Hurtado, \& Newman, 2014).

Mentor Influences. A study by Foertsch, Alexander, and Penberthy (2000) compared program design features with outcomes for participants in summer research programs at 15 Midwestern research universities over a ten-year period, analyzing the rates at which program alumni entered graduate school or professional school, and completed their respective degree programs. One of the key findings of that study was that the quality of the relationship with the faculty mentor is the thing that "makes or breaks" the experience of the summer intern, even when the actual number of contact hours with the faculty member is limited.

Much of the mentoring literature (Haeger, \& Fresquez, 2016; Tenenbaum et al., 2001) has focused on two functions of mentoring: instrumental mentoring that helps students learn essential tasks of science career development, and socioemotional mentoring that supports students' emotional development. Although some research has found additional factors in specific contexts (Haeger, \& Fresquez, 2016; Ortiz-Walters \& Gilson, 2005), the two functions of instrumental and socioemotional mentoring have been consistently identified as critical dimensions of mentoring (Allen, Day, \& Lenz, 2005; Chemers et al., 2011; Baugh \& FagensonEland, 2005; Robnett, Nelson, Zurbriggen, Crosby, \& Chemers, 2018).

Community Involvement (Psychosocial Support). In Gándara and Maxwell-Jolly’s (1999) typology of science support activities, psychosocial support included such elements as 
personal counseling, participating in a cohort of peers, being housed in a particular area on campus, and involving students' families and cultures in the work of the programs. These activities provide work contact that goes beyond the formal lectures or assignments, to help students to know each other and their faculty and to feel included in the group. These activities may be implemented by individual faculty members, by science support programs, by science departments, and by national organizations. Based on earlier work on the Mediation Model (Chemers et al., 2011) and the importance of community building in successful support programs (Stolle-McAllister, Domingo, \& Carrillo, 2011), we use the term community involvement and narrow this construct to reflect opportunities for students to develop a sense of being part of the scientific community.

Academic Support. Science students may have access to many kinds of learning support. Formal and informal tutoring and study groups, learning and study centers, workshops and seminars are a few examples. Orientations and advertising can help students be aware of and make contact with local and national resources for dealing with coursework and other academic tasks such as completing the Graduate Records Exam. Academic counselors help students choose majors, courses, and internships, and help students deal with academic difficulties as they arise. There is empirical support for the value of some of these activities. Tutoring for college students has been found to be especially useful for the students doing the tutoring (Nolan, Hanley, DiVietri, \& Harvey, 2018). The Treisman study group model, which focuses on students' strengths rather than deficits, and cooperative learning groups to help students learn calculus, has been shown to be effective in improving performance, persistence, and graduation (Fullilove \& Treisman, 1990; see also Kudish, Shores, McClung, Smulyan, Vallen, \& Siwicki, 2016). 
Financial Support. Financial support provided to students both in and out of formal science support programs includes scholarships and grants to pay for tuition, fees, and/or living expenses; as well as pay for work in scientific labs both on and off campus. Students highlight the importance of this financial support, which often enables them to work in research labs and focus on their coursework rather than spending time in non-science related jobs (StolleMcAllister, et al., 2010). However we know of no research that compares the effects of financial support with other types of support.

The current research aims to understand the relative contributions of these STEM support experiences, and the pathways by which they affect student commitment to a STEM career. In this research we focused on three promising pathway candidates: science self-efficacy, leadership and teamwork self-efficacy, and identity as a scientist. These psychological mediators were selected due to their extensive representation in research on commitment and achievement in academic performance environments across a number of different areas of psychology (Andersen \& Ward, 2014; Chemers et al., 2011; Richardson, Abraham, \& Bond, 2012) and because they represent higher order versions of more specific processes that have been examined (e.g., affirmation, Cohen et al., 2006, which is a component of identity, Umaña-Taylor et al., 2014).

\section{Psychological Mediators}

Self-efficacy. A vast program of research on self-efficacy (Bandura, 1997) indicates that confidence in one's ability to perform a specific behavior or accomplish a specific task is predictive of performance above and beyond predictions based on objective measures of ability alone (Chemers, Hu, and Garcia (2001); Bandura, 1986; Parker, Marsh, Ciarrochi, Marshall, \& Abduljabbar, 2014; Zimmerman, 1989). Zimmerman (1995) makes a compelling case for the 
mediational role of self-efficacy in academic achievement, arguing that the mediational role is best seen in students' self-regulatory activities in the pursuit of academic goals (Zimmerman \& Ringle, 1981; Zimmerman \& Schunk, 1989; see also Robnett et al., 2015). These effects also manifest in greater persistence in activities related to career objectives, such as continuation in a college major, and working for (and achieving) higher grades (Chemers et al., 2001; Honicke \& Broadbent, 2016; Lent, Brown, \& Larkin, 1986; Manzano-Sanchez, Outley, Gonzalez, \& Matarrita-Cascante, 2018; Multon, Brown, \& Lent, 1991).

One important feature of self-efficacy is “domain specificity.” Individuals may hold very disparate estimations of their capability in differing task domains. In the current research, the two domains that we predict will be most important are beliefs about ability to conduct scientific research (science self-efficacy) and beliefs about the ability to contribute to teamwork in a scientific endeavor (leadership and teamwork self-efficacy).

Science self-efficacy. Most STEM support programs place a great deal of emphasis on an authentic research experience. Some studies have examined how these research apprenticeships affect the knowledge and skills of science learners at the high school and undergraduate levels (Bell et al., 2003; Robnett et al., 2105; Seymour, et al., 2004). These studies found that engagement in authentic science offers the opportunity for students to engage in scientific practices (e.g. using evidence), use scientific and technical language, communicate about the problems of science, and appreciate the slow and deliberate nature of science. Self-efficacy concerning one’s ability to do scientific research is conceptualized as a sub-class of the general notion of academic self-efficacy described above. Our hypothesis is that research experience will enhance science self-efficacy, which will lead to increased commitment to pursuing a career in science. 
Leadership and teamwork self-efficacy. Increasingly, research in STEM fields is conducted by teams rather than individuals working alone (Wuchty, Jones, \& Uzzi, 2007). Although leadership and teamwork self-efficacy has not, to our knowledge, been studied in the domain of scientific research, studies have found it to be a strong predictor in other domains. For example, Chemers, Watson, and May (2000) measured the leadership self-efficacy of undergraduate students enrolled in the Reserve Officer Training Corps (ROTC) who were observed and evaluated for leadership effectiveness during a six-week U. S. Army training program. On every measure of leadership performance (whether rated by peers, instructors, or Pentagon-trained independent evaluators), leadership self-efficacy scores were positively and significantly related to all ratings. Watson, Chemers, and Preiser (2001) found dramatic effects of leadership self-efficacy in their longitudinal study of leadership in men's and women's college basketball teams. Results indicated that the leadership self-efficacy score of the team captain was the best predictor of the collective self-efficacy scores for the team as a whole, and team collective self-efficacy was the best predictor of team success as measured by win-loss record and success in post-season playoffs, far surpassing the predictive effects of "objective" measures of talent.

When a student is exposed to the importance of leadership, as modeled by mentors, and teamwork, as modeled by peers, s/he may come to recognize that to be a good scientist also involves being a good team member. Thus, we hypothesized that, in addition to science selfefficacy, leadership and teamwork self-efficacy would be a mediator of the effects of science support programs.

Student Identity as a Scientist. Studies concerned with student persistence and success in academic settings report that student identity is related to a "sense of fit" with other academics 
and the academic world, in general (Syed et al., 2011). A number of studies have found that identification with “context relevant” identities (e.g., student, scientist, etc.) provides better prediction of academic performance and persistence than racial or ethnic background on its own (Bonous-Hammarth, 2000; Eccles \& Barber, 1999; Osborne \& Walker, 2006; Hazari, Sonnert, Sadler, \& Shanahan, 2010). Identification as a scientist has been viewed as having three overlapping dimensions: competence in valued science practices, performance of these practices that makes them visible to others, and, in response, recognition for that performance by people that matter (Carlone \& Johnson, 2007).

Underrepresented minorities may experience uncertainty about how well they fit in the academic environment (Syed et al., 2011). Perceptions of inadequate capabilities and/or poor fit and identity mismatch can result in withdrawal from academic pursuits and opportunities (Hausmann, Schofield, \& Woods, 2007; Lee, Alston, \& Kahn, 2015; Lewis et al., 2017; Walton \& Cohen, 2007). However, it may be that a research internship, as part of a scientific support program, might provide the opportunity to test one’s ability to learn scientific content and methods. Moreover, the chance to associate with research mentors and other science students might dispel doubts about fit. Of course, a negative experience might also enhance doubts and threats. Accordingly, we hypothesize that identity as a scientist would serve as a mediator between program components and commitment.

\section{Moderation by Ethnicity and Gender}

Although we predict that the model will apply to all students, some relationships might be different for underrepresented minority (URM) students and women of all ethnicities. Although there is a great deal of research on the experiences of URM and female students in STEM (Cheryan et al., 2017; Fouad et al., 2010; Robnett \& Thoman, 2017), there is insufficient 
literature to make predictions about differential relations between program activities and psychological processes. A consistent finding from the intervention literature, however, indicates that those most in need of intervention typically derive the greatest benefits (e.g., Fritz et al., 2004). Thus, our most informed expectation is that the paths from the support activities to the psychological mediators will be stronger for ethnic minorities and women than for whites and men.

Importantly, the value of testing the Mediation Model of Research Experiences does not rest on whether or not there are apparent group differences. That is, the model is not, at its heart, a model of group differences. Rather, the MMRE is a model for explaining why STEM support program activities might be effective for facilitating students' intentions to continue with a STEM career, in the context of existing institutional structures. Developing this knowledge in general, and understanding whether the processes differ for students from different backgrounds, will contribute to the development of stronger support programs, and will inform broader changes in STEM education, such as how to teach and mentor students from diverse backgrounds, and how to create more inclusive learning environments.

\section{The Present Research}

The Mediation Model of Research Experiences was first presented in Chemers et al. (2011). That study reported the results of a web-based survey of student members of the Society for the Advancement of Chicanos and Native Americans in Science (SACNAS). A sample of 665 SACNAS members (327 undergraduates and 338 graduate students and postdoctoral fellows) responded to scales measuring the constructs in Figure 1. The structural equation model analyses supported predictions for both the undergraduate and the graduate student/postdoc samples (analyzed separately). Based on these results, we predict that research experience, 
mentoring, and community involvement (i.e., association with science professionals and students) will be the most powerful predictors of self-efficacy and identity. For the other program elements identified by Gándara and Maxwell-Jolly (1999), academic and financial support, our predictions are less clear (Chemers at al., 2011). Academic support may contribute to learning and skill acquisition, but sometimes carries the stigma of remedial work, possibly undermining self-efficacy perceptions. Academic support is typically aimed at helping students be better students (e.g. performing well on exams) but may not do anything for helping students gain valued scientific skills that are necessary to being successful in authentic STEM setting (e.g. a research lab). Financial support is clearly very important for making the research experience possible, and recipients should be very grateful and positive about it, but there is no reason to believe that financial support will have differential effects on high or low levels of the mediators. We report the findings of two studies testing elements of the Mediation Model of Research Experiences. Study 1 is a retrospective survey of science support program participants as well as science majors not participating in programs, building on Chemers et al.’s (2011) earlier research which focused primarily on students in formal programs from underrepresented minority backgrounds. This study allows us to cross-sectionally test the full mediation model using structural equation modeling. The survey respondents in Chemers at al. (2011) were primarily of underrepresented minority background (74\% of the undergraduate and $87 \%$ of the graduate sample), with an insufficient number of white participants to compare underrepresented minority with nonminority responses. In the current study, we expand the methodologies to include a sample of white students in order to make direct comparisons.

Study 2 provides different information about the STEM support activities and psychological mediators by assessing change across time in a different sample of students who 
were participating in formal science support programs. The pre-post design allowed us to test more directly whether change in our proposed mediators and change in outcome measures result from participation in science support programs. This approach provides important foundational data regarding whether, and to what degree, the model components change as a function of program participation.

In both studies, our goal was not to test the comparative impacts of formal versus informal research programs or to conduct program evaluation, but rather to test our theoretical mediation model (Study 1) and to understand the degree to which the model components are amenable to change through program participation (Study 2). For both studies, we attest that we have reported all relevant measures and conditions, described all data exclusions, and indicate how we determined our sample sizes.

\section{Study 1: A Retrospective Survey of STEM Support Program Participants and Science/Engineering Majors}

\section{Method}

Sample and procedures. We drew our sample from the population of undergraduates who had participated in a STEM support program or majored in a STEM discipline at the University during the academic years 1999/2000 through 2004/2005. The 13 STEM support programs provided lists of their undergraduate participants. In addition, University Institutional Research obtained the names of students majoring in STEM disciplines who had not participated in programs. For our survey sample of non-program participants, we attempted to contact all underrepresented minority (URM) students in order to over-sample this group so that we had sufficient statistical power to test the hypothesized model. For other ethnicities, we drew a 
sample that was equivalent to their representation among all majors; however, final percentages vary because of varying response rates (see Table 1).

We obtained contact information from programs, alumni relations, and institutional research. In order to protect student confidentiality, Institutional Research managed the process of sending an e-mail invitation to each student with an individualized link to the survey site. Program directors alerted their participants to expect the invitation. We made follow-up phone calls to non-respondents for whom we had telephone numbers. The first page of the survey included informed consent information and described the \$5 gift certificate incentive.

There were 502 students who completed the entire survey, a 20\% response rate, which did not differ appreciably across gender or ethnic groups. While low, this response rate is within one standard deviation of the mean reported in a meta-analysis of response rates in web- or internet-based surveys (mean of 68 published surveys was 39.6\%, SD = 19.6\%, Cook, Heath, \& Thompson, 2000). Of greater importance in this study, the respondents represent the entire range of student involvement in science support experiences. At the low end of involvement were those with no program involvement (26.7\%). Another 21.3\% participated informally through research in faculty labs, $24.7 \%$ participated in programs without a research component (e.g., Academic Excellent Program [ACE]), and 27.3\% participated in programs with a research component (e.g., Minority Biomedical Research Support [MBRS]). The ethnic background (Table 1) was 33.86\% underrepresented minority (including 23.90\% Chicano/Latino, 8.17\% African American, and 1.80\% Native American), 39.64\% White, 22.71\% Asian, and 3.78\% other/unknown. Participants' mean age was 23.21 years $(\mathrm{SD}=3.26)$, and 56\% were women.

Measures. Survey measures were developed using both relevant literature and interviews with program staff members and alumni. To ensure that we were using item language and 
content appropriate to the context of these STEM support programs, we interviewed 13 program staff members, 20 faculty mentors, and 9 program alumni. Interview responses were discussed by the research team and integrated into the pilot survey measures. The survey was piloted using a think-aloud protocol with 13 former science support participants, providing further information for refinement of language and response alternatives.

There were two forms of the survey, one for students in science majors, the other for engineering majors. With only one exception (research activities), there were no substantive differences between the two versions; rather, the word "science" was replaced by the word "engineering." For research activities, some items differed between the science and engineering versions of the survey; these are described below. Tests of differences between students responding to the engineering vs. science forms of the survey showed no statistically-significant difference in mean levels of the 10 constructs. Therefore, subsequent analyses combined engineering and science students’ responses. For all scales negatively-worded items were reverse-coded and items were averaged for each scale so that higher values represented greater levels of the construct. The full survey is available at https://osf.io/9y6j7/.

Research activities. An 18-item scale assessed students’ involvement in professional science or engineering activities of varying levels of complexity that would serve to differentiate research from typical classroom science, and differentiate different kinds of research experiences, knowing that there is tremendous variation in what is called a "research experience.” Students responded on a 5-point scale, ranging from 1 (not at all) to 5 (a lot), to questions such as "I participated in scientific research at the university," "I learned technical science skills (e.g., use of tools, instruments, and/or technology)” to “I wrote article(s) for publication.” Ten of the items were adapted from previous research (Chinn \& Malhotra, 2002; 
Kardash, 2000); the remainder were suggested by our interview respondents. Scientific reasoning practices were articulated to be representative of doing “real” science/engineering rather than versions of these practices that students are asked to do in typical science classes, which can be so simplified that they are qualitatively different than the reasoning practices scientists and engineers actually used (Chinn \& Malhotra, 2002). We articulated a list of scientific processes that cut across different research methods (descriptive and experimental) and across varied disciplines (e.g., biology, chemistry, and engineering). However, because of substantive differences between the processes of scientific research and engineering problem-solving, 6 items asked students about parallel steps in each process. Science majors reported their involvement in generating their own research question, identifying/clarifying questions along the way, figuring out what data/observations to collect and how to collect them, interpreting the meaning of data/observations, creating explanations for the study results, and relating research results and explanations to the work of others. Engineering majors reported their involvement in generating an engineering problem to answer, identifying/clarifying sub-problems along the way, identifying and prioritizing the constraints related to an engineering problem, finding solutions to a problem, evaluating how well the solution fit within the constraints, and figuring out how results and explanations related to the work of others. One item, "I wrote article(s) for publication” had low communality with the single factor and was dropped from further analysis, leaving 18 items with Cronbach’s $\alpha$ of .97.

Instrumental and socioemotional mentoring. The instructions for the mentoring section began with an invitation to consider the range of people who might serve as mentors: “Undergraduates are sometimes mentored by many different people: faculty members, program staff, graduate students, peers. Please think back to the mentoring you received, including people 
who were not formally designated as 'mentors."” Mentoring was not defined, allowing us to assess students' subjective perception of this function. The socioemotional mentoring scale was comprised of 16 items with behaviors such as "been warm and friendly" and "listened when you talked” $(\alpha=.95)$. Instrumental mentoring was measured with 6 items, with behaviors such as “given you challenging assignments that presented opportunities to learn new skills" and "helped you figure out for yourself how to understand and explain your research [project] results" $(\alpha=$ .90). Of these items, 12 were adapted from Tenenbaum et al. (2001), who in turn had adapted them from Dreher and Ash (1990); ten were derived from our interviews. Items for instrumental and socioemotional mentoring were interspersed through this survey section, and participants responded on a 5-point scale, ranging from 1 (not at all) to 5 (a lot).

Community involvement. Based on pilot work, we represented Gándara and MaxwellJolly’s (1999) psychosocial support construct with community involvement, the extent to which students were included in the community of scientists and engineers. Community involvement was measured with a 5-item scale written for this study which included items such as "I networked with fellow students" and "I participated in social events with faculty or staff members, and/or fellow students.” $(\alpha=.73)$. Participants responded on a 5-point scale, ranging from 1 (not at all) to 5 (a lot).

Academic support. A 6-item scale for academic support was written for this study and included items such as "I attended academic workshops or seminars to improve my science or math achievement," and "I received tutoring help" $(\alpha=.81)$. These items were based on interviews and the Gándara and Maxwell-Jolly (1999) characterization of this support type. Participants responded on a 5-point scale, ranging from 1 (not at all) to 5 (a lot). 
Financial support. Financial support was measured with a single item on a 5-point scale, ranging from 1 (not at all) to 5 (a lot), "I received financial support (e.g., stipend, tuition or other scholarship, grant, paycheck).” This item was written for the current study.

Science/Engineering Self-efficacy. The work of Bandura (1997), Chemers et al. (2001), and Kardash (2000) guided development of the science/engineering self-efficacy scale. Students read an introduction to the section on "Confidence as a Scientist [or Engineer]" that "assesses your confidence in your abilities to function as a scientist [or engineer].” Respondents indicated the "extent to which you are confident you can successfully complete the following tasks.” Eleven items described specific tasks related to the science (or engineering) process, tasks that comprised part of the research activities scale. Three additional items included understanding ethics, generally functioning as a scientist [or engineer] in a research [engineering] activity, and learning the full range of science [engineering] skills with appropriate training. Responses were made to the 14 items on a 5-point scale that ranged from 1 (not at all confident) to 5 (absolutely confident), resulting in a Cronbach’s alpha of .96.

Leadership/Teamwork Self-efficacy. This scale, adapted from Chemers’ program of research (Chemers, et al., 2000; Watson, et al., 2001), invited students to report on their confidence in leading and working as part of a research team. Leadership was defined in the instructions as "getting people to work together effectively to answer a question or solve a problem (e.g., motivating good performance, dealing with conflict, etc.). Teamwork was described as including communication, collaboration, etc. The 8 leadership items were derived from Chemers et al. (2000), and included: "I know a lot about what it takes to be a good leader." Four items specific to teamwork were written for this study, for example "I have high confidence 
in my ability to function as part of a team.” Students responded to the 12 items on a 5-point scale ranging from one (strongly disagree) to 5 (strongly agree), with a Cronbach’s alpha of .84.

Identity as a Scientist [Engineer]. Respondents were asked to think about themselves and their personal identity, to help us "understand how much you think that being a scientist [an engineer] is part of who you are.” On a 5-point scale ranging from 1 (strongly disagree) to 5 (strongly agree), students indicated their agreement to 13 items such as "In general, being a scientist [engineer] is an important part of my self-image," and "I am a scientist [engineer] $(\alpha=$ .89). Of these items, seven were adapted from Sellers' Centrality Scale (based on his

Multidimensional Model of Racial Identity, Sellers, Smith, Shelton, Rowley, \& Chavous, 1998), and two were adapted from Luhtanen and Crocker’s collective self-esteem scale (1992).

Outcome: Commitment to a science/engineering career. The outcome variable was developed for this study; it measures students' satisfaction with their undergraduate education and intentions to work in the field of science or engineering. Students responded to the five items on a 5-point scale ranging from one (strongly disagree) to 5 (strongly agree). Items included "I feel well prepared to use my understanding of science [engineering] to inform my decisions in daily life and in my career," and "I intend to work in a field of scientific research [engineering]" $(\alpha=.82)$.

\section{Results}

Analysis strategy and preliminary analyses. The conceptual model was tested through a series of structural equation models (SEM) using maximum likelihood estimation in Mplus (Muthén \& Muthén, 2010). To reduce the number of parameters in the model we created item parcels to be used as indicators of the latent constructs. The parcels were created using the itemto-construct balance approach (Little, Cunningham, \& Shahar, 2002) We created three parcels 
each for research experience, instrumental mentoring, socioemotional mentoring, science selfefficacy, teamwork and leadership self-efficacy, and identity as a science student, and two parcels each for community involvement, academic support, and commitment to a science career. Financial support was measured using a single item and was therefore included as a manifest construct in the models.

The analysis was conducted in two steps. First we fit a series of four confirmatory factor analytic models to assess the potential overlap in similar constructs: research experience, academic support, and community support; instrumental mentoring and socioemotional mentoring; science self-efficacy and teamwork/leadership self efficacy; and identity as a scientist and commitment to a science career. Next, we tested a series of structural models to assess the fit of our theoretical model to the data.

Several fit statistics were used to assess how adequately the models fit the data. Absolute model fit was assessed using 1) the chi-square goodness of fit test, which is non-significant in very well-fitting models, 2) two incremental fit indices: the CFI, which compares the model being tested to an independence model, and the TLI, which has the added benefit of correcting for the number of parameters in the model (Hu \& Bentler, 1995); both of which should be greater than .90; and 3) two residuals-based indices: the standardized root mean square residual (SRMR) and the root mean square error of approximation (RMSEA). Lower values of the SRMR and RMSEA reflect better model fit, with values less than .08 considered acceptable (Kline, 2016). We used three metrics for model comparison: 1) the chi-square difference test, 2) the $\Delta \mathrm{CFI}$, and 3) the sample-size adjusted Bayesian Information Criterion (ssBIC). The $\triangle \mathrm{CFI}$ is a useful indicator because it is more conservative than the chi-square difference test (Cheung \& Rensvold, 2002). A difference in CFI values between two models that exceeds .01 is considered 
indicative of worse fit. The ssBIC is useful for comparing non-nested models. Lower values indicate better fit, although there is no agreed upon method for assessing how much lower the value must be to be significant. The three metrics were used as a set when comparing models so as to not let a single index drive our decision-making.

Confirmatory factor analyses. All four of the CFA models yielded excellent model fit (See Table 2 for fit indices). These analyses indicate that the latent constructs, as measured using the item parcels, are empirically distinguishable. To ensure that the parcels load similarly onto the latent factors across the various subgroups in our sample, we conducted four multigroup models for each of the four CFA models (16 CFAs in total), assessing the factor structure across ethnicity, gender, science vs. engineering, and program participation vs. no program participation. Model fit was excellent for all 16 of the models, indicating that there were not any group differences in the factor structure of the constructs (Table 2 for fit indices).

Preliminary model testing: Establishing a baseline model. The hypothesized mediation model (Figure 1) specifies that psychological processes (i.e., science self-efficacy, teamwork and leadership self-efficacy, and identity) mediate the associations between program components (i.e., research experience, instrumental mentoring, socioemotional mentoring, community support, academic support, and financial support) and commitment to a science career. However, we first tested a model that also included direct paths from the program components to commitment (i.e., a model with both direct and mediated effects) as a basis for comparison with the hypothesized mediated model and to ensure that our model would be correctly specified (i.e., would not miss direct effects present in the data). Means, standard deviations, and bivariate correlations are presented in Tables 3 (URM) and 4 (White). A 
summary of fit statistics for all models is presented in Table 5. Students who did not identify as URM or White were dropped from these analyses.

Fit indices for the full model (Model A) suggested an excellent fit, $\chi^{2}(258)=538.43, p<$ $.001, \mathrm{CFI}=.97, \mathrm{TLI}=.96, \mathrm{SRMR}=.04, \mathrm{RMSEA}=.05(90 \%$ C. I. $=.05, .06)$. However, there were several non-significant paths in the model. Socioemotional mentoring, academic support, and financial support were not predictive of commitment or of the three mediators. Further, teamwork and leadership self-efficacy was not predictive of commitment, suggesting that it is a not a mediator of program components. Based on the results of this preliminary analysis, these four constructs were removed from the model to produce a "reduced full model" (Model B) that included all direct and indirect paths from the three remaining program components (research experience, instrumental mentoring, and community involvement) to the two remaining mediators (science self-efficacy and identity as a scientist) and the outcome (commitment to a science career). Fit for the reduced full model was excellent, $\chi^{2}(105)=278.16, p<.001, \mathrm{CFI}=$ $.97, \mathrm{TLI}=.96, \mathrm{SRMR}=.05, \mathrm{RMSEA}=.07(90 \%$ C. I. $=.06, .08)$.

Testing the mediation model. The next step was to test the proposed fully mediated model (Model C) against the reduced full model (Model B). Fit for the fully mediated model was excellent, $\chi^{2}(108)=293.64, p<.001, \mathrm{CFI}=.97, \mathrm{TLI}=.96, \mathrm{SRMR}=.05, \mathrm{RMSEA}=.07(90 \% \mathrm{C}$. $\mathrm{I} .=.06, .08)$. Comparing the reduced full model and the fully mediated model using model comparison statistics provided a mixed picture. Although the $\triangle \mathrm{CFI}$ value of -.002 suggested that the two models did not differ, both the chi square difference test, $\Delta \chi^{2}(3)=15.48, p=.001$, and the ssBIC (7.26 lower for the reduced full model) indicated that the fully mediated model had significantly worse fit. Accordingly, we examined results from the Lagrange Multiplier Tests and examined the standardized residuals to determine whether any of the direct paths should be 
returned to the model. These analyses suggested that the source of relatively poor fit in the fully mediated model was the lack of a direct path from instrumental mentoring to commitment. Adding this path to the model (Model D) resulted in excellent fit, $\chi^{2}(107)=281.08, p<.001$, CFI $=.97, \mathrm{TLI}=.96, \mathrm{SRMR}=.05, \mathrm{RMSEA}=.07(90 \% \mathrm{C} . \mathrm{I} .=.06, .08)$. We next dropped the two non-significant paths (instrumental mentoring $\rightarrow$ science self-efficacy and instrumental mentoring $\rightarrow$ identity), resulting in a trimmed, partially mediated model (Model E), $\chi^{2}(109)=$ 281.24, $p<.001, \mathrm{CFI}=.97, \mathrm{TLI}=.96, \mathrm{SRMR}=.05, \mathrm{RMSEA}=.07(90 \%$ C. $\mathrm{I} .=.06, .08)$. The trimming did not result in a significant reduction in fit, $\Delta \chi^{2}(2)=0.158, p=.69, \Delta \mathrm{CFI}<.001$. A chi-square difference test comparing Model E and Model B indicated that this latest, partially mediated model did not have significantly worse fit than the fully mediated model, $\Delta \chi^{2}(4)=$ $3.08, p=.56, \Delta \mathrm{CFI}<.001$.

Testing the multiple group mediation model: Moderation by ethnicity. Working from the previous trimmed partially mediated model (Model E), our next objective was to determine whether elements of the model varied significantly by ethnic group (URM and White). We first compared a model that was fully constrained across ethnicity, with all paths set to be equal for both groups $\left(\right.$ Model F). The fit of this model was comparable to the previous Model E, $\chi^{2}(250)=$ 499.79, $p<.001, \mathrm{CFI}=.96, \mathrm{TLI}=.95, \mathrm{SRMR}=.08, \mathrm{RMSEA}=.07(90 \%$ C. I. $=.06, .08) . \mathrm{We}$ then compared the fully constrained model to a model that was fully unconstrained, allowing all structural paths to vary (Model G). The chi square difference test, $\Delta \chi^{2}(10)=27.96, p=.002$, and the ssBIC (.573 higher) suggested that the fully constrained model fit the data significantly worse than the fully unconstrained model, but the $\triangle \mathrm{CFI}$ value (.004) indicated no difference. These data suggest that the model would benefit from allowing the paths to vary by ethnic group. Although the unconstrained model had excellent fit, examination of the standardized residuals indicated 
that there was one more important association that we had failed to model: a path from science self-efficacy to identity ${ }^{2}$. Adding this path to the model resulted in a significant increase in fit over the fully constrained model (Model F), $\Delta \chi^{2}(12)=47.01, p<.001$, ssBIC 13.58 lower, $\Delta$ CFI value $=.006$, for a final fit of $, \chi^{2}(238)=452.78, p<.001, \mathrm{CFI}=.96, \mathrm{TLI}=.96, \mathrm{SRMR}=.05$, RMSEA $=.07$ (90\% C. I. $=.06, .08) ;$ Model H).

The final model (Model H; Figure 2) indicated that science self-efficacy and identity as a scientist jointly mediated the association between research experience and commitment to a science career. Science self-efficacy and identity as a scientist also mediated the association between community involvement and commitment to a science career; there were no direct paths from these two predictors to commitment. In contrast, instrumental mentoring had a direct path, but no indirect paths, to commitment to a science career. Self-efficacy mediated the association between community involvement and commitment for URM students only, as the path from community involvement to self-efficacy was not significant for White students. Although both self-efficacy and identity predicted commitment, the nature of the association among these three constructs varied by ethnicity. The association between science self-efficacy and commitment to a science career was partially mediated by identity more strongly for URM students than Whites. Furthermore, the association between identity and commitment was stronger for White students $\left(b^{*}=.66\right)$ than for URM students $(\beta=.41)$. In terms of the full model, a moderate amount of variance was explained for both self-efficacy $\left(R^{2}=.30\right.$ for Whites, .41 for URMs) and identity

\footnotetext{
${ }^{2}$ Although it is mathematically equivalent to model this path in the other direction, identity predicting science selfefficacy, we believe there is more theoretical support for our chosen model. For example, social cognitive career theory (Lent, Brown, \& Hackett, 1994) suggests that developing self-efficacy in a domain leads to refined interests in pursing a career in that domain. Similarly, Erikson's (1968) theory of identity development stipulates that individuals commit to identities after exploring what they are good at and have interest in.
} 
( $R^{2}=.27$ for Whites, .36 for URMs), and a substantial amount for commitment to a science career $\left(R^{2}=.79\right.$ for Whites, .60 for URMs).

Post-hoc analyses: Moderation by gender. Although ethnicity was the primary comparative factor of interest, we also conducted a multi-group model that tested for differences in path coefficients by gender, collapsed across ethnicity. Using the trimmed partially mediated model (Model E) as our starting point, we found that the difference in fit between the fully unconstrained model and the fully constrained model was not significant, $\Delta \chi^{2}(10)=15.90, p=$ $.10, \Delta \mathrm{CFI}=-.001$., suggesting that, as a whole, the model does not benefit from allowing paths

to vary by gender, and therefore the patterns of relationships are the same for women as they are for men.

In sum, science self-efficacy and identity as a scientist operated as predicted, fully mediating the effects of research experience and community involvement on commitment to a career in science. In contrast, the effect of instrumental mentoring was direct, and not mediated through the psychological variables. One mediator (leadership/teamwork self-efficacy) was not predictive of the outcome variable. With few exceptions, results were the same for white and URM students and for male and female students.

\section{Study 2: A Pre-Post Study of Students Enrolled in Formal Science Support Programs}

The results of Study 1 provided strong support for the general idea that psychological mediators are important to consider in this domain, and moderate support for the exact predictions of the proposed model. However, participants were reporting retrospectively on these measures, and the analysis was cross-sectional. Thus, statements about causality derived from these data must necessarily be tentative. Study 2 was designed to provide additional information concerning the role of the components of science support experiences (including 
research experience, mentoring, and community involvement) in affecting self-efficacy, identity, and commitment to science. By using a pre-test/post-test design we are able to address two needs: 1) provide data on whether the model components changed over time during participation in a STEM support program and 2) to make stronger statements about the causal role played by the program elements. As in Study 1, our goal was not to test the comparative impacts of formal versus informal research programs nor were we evaluating the effectiveness of individual programs. Instead, our goal was to further examine general causal processes.

\section{Method}

Sample and procedures. Undergraduates who began one of 10 science and engineering support programs with a research component in the summer and fall 2006 were invited to participate in the study. These programs included local implementations of national programs such as MBRS and the Center for Adaptive Optics (CfAO) Internship Program. Program managers provided time at the beginning and end of the programs for students to participate in the surveys and scientific reasoning simulations (the latter are not reported in this paper). A total of 77 students (85.55\% of eligible students) completed the survey at Time 1 . Although all of these students finished their programs, seven did not complete the post-program survey. These students missed the final data collection due to conflicts with poster preparation or because their internships or home-campus courses began before the summer program ended. There were no apparent differences in attrition by program, gender, or ethnicity. There were a total of 70 students with both T1 and T2 survey data. Most (76\%) of these students were in summer-only programs (e.g., CfAO), with 8-10 weeks between pre- and post-program data collection. The remainder were in academic year-long programs (e.g., MBRS) that began either in summer or fall 2006 and continued through the 2006-2007 academic year. The sample was balanced by 
gender $(53 \%$ men), with a mean age of 21.94 years $(\mathrm{SD}=3.79)$. The ethnic background was 50\% URM (of these, 20\% were African American and 80\% were Mexican American or other Latino), 38\% White, and 12\% Asian American. The following analyses dropped the Asian American sample, resulting in an analytic sample size of 63. Students who completed all data collection received a $\$ 100$ gift certificate.

Measures. With a few exceptions, as indicated below, the constructs and the scales to measure them were identical with those in Study 1. In order to reduce participant fatigue, we shortened some scales by removing items that overlapped in content with others, or by dropping items that had the lowest loadings. We also removed reverse-scored stems, as they had lower loadings on the scales than other items. Other changes are indicated below. We used separate versions of the survey for science and engineering students only for clarity of wording. Full versions of the surveys are available at https://osf.io/9y6j7/.

Research experience. One item was dropped from the Study 1 scale. The remaining 17 items described activities used in the prior scale, with alpha coefficients of .95 and .93 for the pre- and post-program administrations, respectively.

Instrumental and socioemotional mentoring. In Study 2, we gave a more precise definition of mentoring than we had done in Study 1: "A mentor is anyone more experienced than you who has given you individual support related to your development as a science student.” As in the first study, students reported the extent to which one or more of their mentors during their undergraduate experience displayed particular behaviors, using a 5-point Likert-type scale ranging from 1 (not at all) to 5 (to a very large extent). We added one item to the instrumental mentoring scale from Study 1. This yielded a 7-item scale, with internal consistency of .85 and .80 for pre- and post-program surveys. We pared the Study 1 socio-emotional 
mentoring scale from 16 to 8 items, with alpha coefficients in Study 2 of .91 and .92 for pre- and post-program surveys respectively.

Community involvement. This scale consisted of the same 4 items in Study 1, including “I networked with fellow students” and "I attended academic workshops," with somewhat lower alpha coefficients, .73 and .68.

Academic support. Three items from the Study 1 academic support scale were retained and 3 items were added, including "I received advice about how to cope with academic setbacks.” The resulting six items were internally consistent, with alpha coefficients of .84 and .85 for pre- and post-program surveys.

Financial support. The single-item financial support scale of Study 1 was changed to two items, "I received help in paying for my tuition” and "I received a scholarship or grant” ( $r=$ .74 and .65).

Psychological processes. Science self-efficacy was reduced by 4 items, yielding a 10item scale with alpha coefficient of .93 for both pre- and post-program surveys. The leadership/teamwork self-efficacy scale was reduced from 12 items in Study 1 to 9 items, maintaining high alpha coefficients (.88 and .92 for pre- and post-program surveys, respectively). The identity as a scientist scale was reduced from 13 items in Study 1 to 7 items. The resulting scale had high internal consistency (.87 and .90 for pre- and post-program administration, respectively).

Commitment to a science/engineering career. To attain a sharper focus on commitment to a science career, we pre-tested a set of 19 potential items with 568 participants in an introductory psychology subject pool. Examples of the 7 items that were ultimately included in this scale are: "I intend to work in a job related to science/engineering," and "I expect a career in 
this field will be very satisfying.” Two of these items were similar to those in Study 1. Internal consistency of this scale was high (.92 and .95 for pre- and post-program administration).

\section{Results}

Change in constructs, moderated by ethnicity and gender. We conducted a series of repeated measures ANOVAs to test for change over time (i.e., change due to exposure to the program components) in the mean levels of the constructs, and whether the change was moderated by ethnicity (see Table 6 for correlations and descriptive statistics for all study variables). Analyses indicated no clear violations of assumptions of independence, normality, or homoscedasticity. Ten separate models were estimated, one for each of the ten constructs. In each analysis, Time was represented as a two-level repeated measures factor (e.g., Time 1 research experience and Time 2 research experience) and ethnicity was modeled as a two-level (White and URM) between-subjects factor (there were too few Asian American students to include in these analyses). We also conducted analyses with gender as the moderator, but did not find any significant main effects or interactions. Thus, only data from the ethnicity models are presented.

The ANOVA for research experience revealed a significant within-subjects effect of time, $F(1,61)=103.24, p<.001, \eta_{\mathrm{p}}^{2}=.63$, and a significant time by ethnicity interaction, $F(1$, $61)=13.02, p=.001, \eta_{\mathrm{p}}^{2}=.18$. Taken together, these results indicate that, on average, participants increased their levels of research experience over time, but URM students (Time 1 $M=2.04, S D=0.87$; Time $2 M=3.52, S D=0.64 ; d=1.61$ ) reported a significantly greater increase than White students (Time $1 M=2.60, S D=0.97$; Time $2 M=3.30, S D=0.74 ; d=$ 1.18). 
The ANOVA for instrumental mentoring yielded similar results. There was a significant within-subjects effect of time, $F(1,60)=14.65, p<.001, \eta_{\mathrm{p}}{ }^{2}=.20$, and a significant time by ethnicity interaction, $F(1,60)=8.25, p=.006, \eta_{\mathrm{p}}{ }^{2}=.12$. Results from the interaction indicated that URM students (Time $1 M=3.05, S D=0.88$; Time $2 M=3.74, S D=0.74 ; d=0.76$ ) increased their reports of instrumental mentoring over time, whereas White students remained relatively flat (Time $1 M=3.45, S D=0.81$; Time $2 M=3.55, S D=0.64 ; d=0.15$ ). Only the within-subjects effect of time was significant for socioemotional mentoring, $F(1,59)=5.52, p=$ $.02, \eta_{\mathrm{p}}{ }^{2}=.09$, indicating that, on average, students increased through their time in the program (Time $1 M=3.52, S D=.74$; Time $1 M=3.73, S D=.84 ; d=0.32$ ).

For community involvement the within-subjects effect of time was significant, $F(1,61)=$ 9.33, $p=.003, \eta_{\mathrm{p}}^{2}=.13$, corresponding to average increases over time (Time $1 M=2.54, S D=$ 0.96; Time $2 M=2.89, S D=0.97 ; d=0.40)$. The main effect of ethnicity was also significant, $F(1,61)=9.18, p=.004, d=.60, \eta_{\mathrm{p}}^{2}=.13$. URM students $(M=2.99, S D=1.03)$ reported higher levels of community involvement than did White students $(M=2.40, S D=0.94)$. The time by ethnicity interaction was not significant.

Time was the only significant effect for academic support, $F(1,61)=9.04, p=.004, \eta_{\mathrm{p}}{ }^{2}$ $=.13$, with students reporting greater academic support over time (Time $1 M=2.46, S D=0.83$; Time $2 M=2.74, S D=0.89 ; d=0.40$ ). No model terms were significant for financial support. Results for change in science self-efficacy revealed only a significant within-subjects effect of time, $F(1,61)=22.52, p<.001, \eta_{\mathrm{p}}{ }^{2}=.27$, indicating that students' self-efficacy increased over time (Time $1 M=3.31, S D=0.83$; Time $2 M=3.79, S D=0.66$; $d=0.67$ ), but that the change was not moderated by ethnicity. None of the model terms were significant for teamwork/leadership self-efficacy. 
The ANOVAs for identity as a scientist and commitment to a science career also did not yield any significant findings. The lack of findings may be due, in part, to the consistently high ratings of both identity (Time $1 M=3.84, S D=0.66$; Time $2 M=3.99, S D=0.78 ; d=0.24$ ) and commitment (Time $1 M=4.51, S D=0.55$; Time $2 M=4.45, S D=0.59 ; d=-0.12$ ).

Implications of change in constructs. We conducted a series of pre-post regression analyses to examine the implications of changes over time in two sets of relationships: a) the science support experiences for the mediators and b) the mediators for commitment to a science career (see Table 7). For each analysis the Time 2 construct was used as the dependent variable. Using hierarchical multiple regression, the corresponding Time 1 construct was entered in Step 1 to remove variance associated with stability over time (e.g., Time 1 commitment predicting Time 2 commitment). In Step 2 we added the change in the predictors of interest, calculated as the difference between Time 2 and Time 1 so that higher values correspond to an increase over time. Using change scores in the analyses allowed us to test how changes in students' experiences during the period in which they were participating in the programs were associated with their attitudes at the end of the program. We conducted four regressions in this way: 1) change in science support experiences (research experience, instrumental mentoring, socioemotional mentoring, community involvement, academic support, and financial support) predicting Time 2 science self-efficacy, 2) change in science support experiences predicting Time 2 teamwork/leadership self-efficacy, 3) change in science support experiences predicting Time 2 identity as a scientist, and 4) change in science self-efficacy, teamwork/leadership self-efficacy, identity as a scientist predicting Time 2 commitment to a science career.

In the first model, we found that change in community involvement $\left(b^{*}=.52, p=.001\right)$ predicted Time 2 science self-efficacy, over and above Time 1 science self-efficacy $\left(b^{*}=.71, p\right.$ 
$<.001)$. The second and third models, predicting Time 2 teamwork/leadership self-efficacy and

Time 2 identity as a scientist, respectively, from change in program components did not result in any significant predictors beyond the initial levels. In the fourth and final model, where Time 2 commitment was predicted from the change in the three psychological mediators, we found that only change in identity was a significant predictor $\left(b^{*}=.28, p=.007\right)$ beyond Time 1 commitment $\left(b^{*}=.58, p<.001\right)$.

Finally, we tested for whether ethnicity or gender moderated any of the associations between the change in constructs and the dependent variables. Due to sample size constraints we tested each moderator separately (e.g., how ethnicity moderated the association between change in research experience and Time 2 identity was conducted in a separate regression analysis from how ethnicity moderated the association between change in academic support and Time 2 identity). None of the interaction terms in any of the models were significant.

\section{Discussion}

The purpose of the present research was to develop a deeper understanding of the psychological processes that may help explain the effectiveness of STEM support activities among ethnically-diverse college students. This goal was executed through two studies, one that examined how psychological factors mediated the association between STEM activities and commitment to a career in STEM, and the other that examined how the model components changed over time in the context of program participation. Taken together, and in light of past work on the MMRE (Chemers et al., 2011), the results of these two studies suggest that the Mediation Model of Research Experiences is a useful model for understanding how aspects of science support programs can translate into commitment to a career in science. In particular, the findings from Study 1 indicate that science experiences such as being engaged in research, being 
mentored, and having the opportunity to associate professionally and socially with other scientists have their effects on student career goals at least in part through the mechanisms of increased self-efficacy in the conduct of scientific research and increased feelings of identity and belongingness in the scientific community. The findings from Study 2 provide initial support for the idea that the program components and psychological mediators can change through program participation, and that, in some cases, change in program components is associated with change in the psychological mediators.

The findings from Study 1 indicated an empirical model that was scaled down from the full conceptual model. A key finding, that is consistent with past tests of the model (Chemers et al., 2011), is that science self-efficacy and identity as a scientist jointly mediated the associations between both research experience and community involvement to commitment to a career in science. Moreover, identity as a scientist partially mediated the association between science selfefficacy and commitment to a science career. This pattern of self-efficacy affecting identity and identity affecting commitment to a career is in close agreement to Lent's social cognitive model of career choice. That model sees self-efficacy as a necessary precursor to the development of interest in a particular career (Brown \& Lent, 1996). In other words, we are drawn to what we are good at. In this study, we uncovered some specific science support experiences that appear to drive self-efficacy and identity. This replicated set of findings provides robust evidence for identity and self-efficacy as intertwined psychological processes that underlie the utility of engaging students in research and integrating them into a community of scientists. That there was no residual direct effect from program components to commitment suggests that program activities are important for instilling a sense of commitment insofar as they contribute to students' STEM identities and feelings of STEM efficacy. This replicated finding has 
implications for program design, and STEM education more generally, points to which we return later.

Additionally, instrumental mentoring had a direct path to commitment—-the only such direct path observed in the model. This path might be explained by the fact that some mentoring occurs outside the context of collaborative research with students. For example, mentors such as support program staff members might influence a student's career directions through advice on how to build an effective curriculum vitae or tips for assembling a strong application for graduate school. In other words, faculty members are not the only individuals who can serve as mentors for students, and there may be important mentoring that occurs outside of the research apprenticeship (DuBois \& Silverthorn, 2005; Hurd, Tan, \& Loeb, 2016).

Importantly, consistent with our past work (Chemers et al., 2011), socioemotional mentoring, academic support, and financial support were not found to be significant predictors of commitment or the psychological mediators, nor was teamwork and leadership self-efficacy found to be an active psychological mediator. We have no direct evidence to bear on the absence of these relationships. Socioemotional mentoring might be more critical in later stages of the educational pipeline (i.e., graduate school), when schooling becomes more closely aligned with students’ career paths (Chemers et al., 2011). In contrast, when just beginning in a field it might be more important for students to receive mentoring aimed at the practices within the discipline. Academic support (e.g., tutoring), is sometimes seen as remedial, and often aimed at improving performance in tests rather than gaining competency as a practicing scientist or engineer, and perhaps that is why it was not associated with self-efficacy or identity. There is little doubt that financial support is extremely important to students, often being the only way that they could spend time in a research experience. On the other hand, given that many of the students in our 
study (about half of participants in Study 1 and all in Study 2) have received enough support to allow them to participate in a program, there is no theoretical reason to believe that having more or less financial support should strongly affect identity or self-efficacy. The findings could be different when considering only students not participating in programs. Thus, financial support might be important only insofar as it allows students to gain access to the full range of support activities available and to have adequate time to devote themselves to research activities. Finally, one possible explanation for the lack of findings for teamwork and leadership self-efficacy is that scores on the measure were generally quite high, and may have produced a ceiling effect that made it difficult to assess relationships with other variables (due to low variance). A more sensitive instrument might be necessary in future research. In hindsight, though, we suspect that there is a substantive explanation that is even more important in understanding these results. Undergraduate students participating in scientific research may not be fully aware of the team nature of scientific research and were too inexperienced to be able to act as leaders, or worked one-on-one with a mentor and did not gain what they perceived to be a team experience. There is some evidence that leadership/teamwork self-efficacy becomes increasingly important as science students move through the pipeline and take on more and more responsibility for their own research (Chemers et al., 2011).

The findings from Study 2 complement those of Study 1. Using a pre-post design, the aims of Study 2 were to a) assess whether the program components and psychological mediators changed as students participated in a science support program and 2) assess whether change in support activities were associated with change in the mediators. With respect to the first aim, participants reported higher levels of four out of five program components at Time 2 as compared to Time 1 (no difference was seen in financial support); thus programs seem to be 
successful in providing the elements that Gándara and Maxwell-Jolly (1999) argued were important in encouraging underrepresented minority student participation in science. Indeed, programs were successful in reducing or eliminating the gap between URM and white students in two program components: research experience and instrumental mentoring-components found to be important in Study 1 and in the previous test of the model (Chemers et al., 2011). This suggests that providing URM students access to science support programs is an important mechanism for "leveling the playing field."

We also tested whether levels of the psychological mediators increased during the course of program participation. This was the case for science self-efficacy, with URM and white students showing equally impressive gains through the course of the programs. This gain is especially notable because most students (70\%) were involved in a short-term program that only lasted for eight weeks. In contrast to the change in science self-efficacy, there were no changes over time for leadership/teamwork self-efficacy or for identity as a scientist. It was surprising that identity as a scientist did not show changes over time in Study 2. The difference in means were in the direction of an increase, but the increase was small $(d=0.24)$ and the study may have been too underpowered to detect it. Alternatively, it may be that students who apply to these selective science support programs are already highly identified with the field of science and that we did not have enough pre-program variance on this measure to be able to assess change over time (which is supported by the descriptive statistics). For highly identified samples such as these, a more sensitive instrument might be necessary. Similarly, commitment to a career in science did not change over time, but looking at the data, students were already highly committed to their careers, and therefore there was little room for increases. 
In sum, the findings for the first aim of Study 2 provide a mixed result: program components changed over time- - which is to be expected, but nevertheless important to document—whereas the psychological processes were relatively more resistant to change. There was, however, evidence of change for self-efficacy, and identity change was in the correct direction, providing some support for the model but also suggesting that perhaps change is a slower process for these constructs. Longitudinal studies that cover a broader range of time will be necessary to conduct a proper test.

The second aim of Study 2 was to assess whether change in support activities was associated with change in the mediators in order to make stronger claims about causality in the model. Using Time 1 scores as controls for each participant we examined the effects of reported changes in program components on Time 2 science self-efficacy, teamwork and leadership selfefficacy, and identity as a scientist. We found that changes community involvement was a significant predictor of Time 2 science self-efficacy, even after controlling for Time 1 science self-efficacy. In contrast, none of the predictors were significant for teamwork and leadership self-efficacy or identity as a scientist. The finding for community involvement is consistent with Study 1, and provides some initial evidence for the importance of social aspects of students' participation in support programs, in terms of connections with the academic community, particularly for building self-efficacy.

More consistent with findings from Study 1, the multiple regression analyses also revealed that change in identity from Time 1 to Time 2 was a significant predictor of Time 2 commitment, whereas changes in science self-efficacy and teamwork and leadership selfefficacy were not. This finding is consistent with the literature on identity development going all the way back to Erikson (1968; see also Azmitia et al., 2008). Our findings show the importance 
of career identity, of identification with the community of scientists or engineers, in generating commitment to such a career. These data also dovetail with those reported above, which collectively point to the importance and value of students' feelings that they belong and are integrated into the community of scientists (see also Hurtado \& Ponjuan, 2005).

\section{Ethnicity and Gender Differences}

We were very sensitive to possible ethnic or gender differences in the relationships that we observed, and we tested for those effects in each study. Overall, the effects of these demographic variables were neither strong nor pervasive, nor easily integrated into a comprehensive explanation. In Study 1, a few paths were stronger for URM or white students, but not in a theoretically predictable way. One exception is that the path from community involvement to science self-efficacy was much stronger for URM students compared to White students (this path was also observed in Chemers et al., 2011, but that study had few White students so there were no comparisons with URM students). This finding fits with a body of research pointing to the importance of embeddedness and relations within a community of scientists for URM students (Chemers et al., 2011; Museus, Palmer, Davis, \& Maramba, 2011). There were no gender differences in the model in Study 1, and no ethnic or gender differences in the regression analyses in Study 2. For some science support experiences (research experiences, instrumental mentoring), URM students showed larger gains over the course of the programs, suggesting that these programs help to level the playing field between URM and white students. Taken together, our analyses by ethnicity and gender suggest that our mediation model is applicable across variations in these social groups. Although we know that ethnic minorities and women are under-represented in STEM fields, our findings suggest that once they are involved 
with STEM, the psychological processes involved with persistence are similar to whites and men.

It is important to note, however, that we analyzed for differences by ethnicity and gender separately. Indeed, for future research it will be useful to examine both ethnicity and gender simultaneously to understand how the intersections of these identities matter for involvement in STEM. For example, although Asian Americans are not considered to be underrepresented in STEM, in Study 2 we anecdotally observed that Asian American females were more likely to drop out the programs over time. This highlights the need to consider both ethnicity and gender when conceptualizing underrepresentation broadly (Cole, 2009) and in STEM in particular (Robnett, Ruvalcaba, Syed, \& Chemers, in press). It would also be useful to examine different STEM fields separately, given that disciplines such as biology differ quite a bit in their demographic profile from disciplines such as computer science or mathematics. Our study was not able to capture such fine-grained differences.

\section{Theoretical Implications}

The findings in the present investigation have implications for theory and research on student success in STEM. First, this study contributes to the very small number of studies that have simultaneously examined the impact of the five categories of science support experiences identified by Gándara and Maxwell-Jolly (1999; see also Chemers et al., 2011). Given the high correlations among these different program components, it is useful to know which ones have the most predictive power. Two of the five program activities-academic support and financial support-were not significant predictors of the psychological mediators or commitment in either

study (nor were they in our other work based on this model; Chemers et al., 2011). These findings suggest that any benefit presumed to be realized as a result of these components is likely 
due to their relations with research experience, mentoring, and community involvement. Thus, these latter constructs that demonstrated predictive power are critical to include in future investigations of this sort.

The Mediation Model of Research Experiences (MMRE) that we advanced in the current work has implications for future theorizing about how support programs-and the beneficial impact of research participation more broadly_operate. Our findings indicate that programs are successful not because they simply provide students with necessary experience or specific skills, but rather because they instill in students a sense that they are capable to do the work and that they fit in with others who do so. In other words, our model suggests the need for further theory and research on how psychosocial factors are related to academic factors (see Robbins et al., 2004).

The current study used an individual differences and developmental approach to understand students' experiences in STEM. While this approach is useful and important, it is also limited as one level of analysis within a much broader system. Comprehensive models of STEM participation should also take into account the structural barriers to entry and persistence to STEM careers and post-secondary education in general (Cooper, Chavira, \& Mena, 2005). Additionally, such a broader perspective would be complemented by a more micro-analytic approach that examines STEM participation as a daily, context-specific practice (e.g., Sadler, 2009). This work is important for understanding the situated nature of STEM participation, much of which is what ultimately is captured when assessing broad individual differences such as selfefficacy. Taking all of these levels into account is nearly impossible for any single study, but we would do well as a field to coordinate and integrate across levels as much as possible. Eccles’ (2009) socioculturally embedded expectancy value model of achievement begins to take such an 
approach, as it conceptually integrates these different levels. Empirical research with the model, however, has tended to focus on the individual difference and developmental aspects. Moreover, research with the expectancy value model in the STEM context has generally not examined the critical program components included in the MMRE, particularly research experience (e.g., Andersen \& Ward, 2014). Future work would be best off integrating developmental and individual differences approaches that are grounded within the actual experiences of STEM students. Overall, there is a need for deeper and stronger theorizing about causes, mechanisms, and outcomes associated with under-representation in STEM. The current literature mostly relies on boutique or piecemeal theories that do not take into account the full context of STEM (e.g., expectancy value theory, self-efficacy). That is, theorizing on under-representation in STEM should not only account for the substantive experiences of the students, but also the nature of their specific educational situations (e.g., barriers to entry vs. persistence vs. success at different levels of schooling). We believe that our collective empirical work contributes to this goal, but that there is still much work to do.

\section{Implications for Science Support Program Design}

Although our studies were not program evaluations, our findings nevertheless have potential implications for program design and operation. The central mediating role of the psychological variables of self-efficacy and identity suggests that they merit close attention in future research and in program design and evaluation. Mentors and program staff should be attuned to changing levels of these variables, and special efforts should be made to strengthen programs in these areas, for example through mentor training, or program components that explicitly support the development of strong research skills rather than assuming students will automatically gain them by being placed with a research mentor. More importantly, the findings 
highlight the reason why the program components identified by Gándara and Maxwell-Jolly (1999) work; specifically because they may help foster a sense of self-efficacy and identity. These findings suggest that simply exposing students to authentic research is not necessarily enough to foster a commitment to pursue a science career. Rather, that research experience should be carefully structured to ensure that it contributes to the psychological processes we identified.

Similarly, our findings in Study 2 make a case for not focusing solely on the research experience itself. Change in community involvement was the only significant predictor of Time 2 self-efficacy. Moreover, change in identity was a predictor of Time 2 commitment. Thus, support programs should continue to focus on ways in which they instill a sense of belongingness and connection amongst the students. In other words, it would be unwise to focus on academic and scholarly activities (e.g., research experience, academic support) without also considering social activities. To be clear, by social activities we do not mean simply socializing with other students and faculty. Whereas such activities may be helpful, what seems to be more valuable are aspects of programs that foster social connectedness in the context of STEM, and open opportunities for learning about and valuing students' backgrounds. Programs in our study, and others throughout the country, often have components that may serve in this capacity, such as weekly meetings in which students share their research projects and a professional who facilitates productive mentoring relationships. Future research could take this further and look more closely at the inner workings of support programs, and which components affect science identity and self-efficacy. Indeed, we urge caution in implementation of these ideas. It is no simple matter to implement changes in program activities to enhance identity and self-efficacy, 
and future research should focus on this very issue to better inform actual practice. The current findings simply suggest that they should be considered.

Our findings have practical implications for STEM education beyond STEM support programs, which can be applied to engaging students in research in any context (not necessarily through support programs), mentoring, laboratory courses, and the growing trend toward studentcentered active learning courses. An important aspect of our study was how we defined "research experience,” acknowledging the wide variability students experience, and aligning our survey items with STEM practices that are more authentic to real world science and engineering (e.g. "I created my own explanation for the results of a study/research project”). Our findings make a connection between students gaining these experiences, and commitment to a STEM career, mediated by science self-efficacy and identity. A curricular focus on teaching and learning STEM practices might be more than just good preparation for students pursuing STEM careers it might also build the STEM self-efficacy and identity needed to persist in a STEM career. Similarly, a "research experience" that does not provide opportunities for students to have meaningful, challenging experience with these practices may do little for their self-efficacy and identity.

Finally, it would be important for future research to examine in greater detail some of the mentoring and support functions that faculty, staff, and fellow students provide. For example, a great deal of what is communicated in STEM support programs has to do with building students' social capital; providing them with the knowledge they need for how to apply to graduate school and/or employment. Examining what these support functions are, how they take place, and who provides them would yield greater information about how support programs can successfully operate and contribute to the psychological processes that we identified as important. 


\section{Limitations and Future Directions}

We recognize some important limitations in these studies that affect their interpretability and application. For one, the studies relied on self-report measures. This was a necessary limitation in Study 1 because we were attempting to reach as many science students and program participants as possible using limited resources. It was also a necessary limitation of Study 2, given that program staff were able to give us only a short amount of time with participants (who are generally kept very busy with program activities). Moreover, the measures were developed for this specific study. Although we conducted psychometric analyses, more rigorous tests of the reliability and validity of the measures should be undertaken. For Study 1, our response rate was lower than is ideal. This suggests that we should be cautious in generalizing results because there may be important differences between responders and non-responders. Due to the relatively small sample in the context of a complex SEM model, we relied on using item parcels as indicators of the latent factors, a practice that continues to be controversial. Further replication of the mediation model with other samples will help to demonstrate the generalizability of this model. Study 1 was also retrospective, with the attendant possibility of memory inaccuracies (with variations depending on whether the participant was remembering events from one or five years previously). This limitation was ameliorated by the fact that Study 2 used a pre-post design; however, further large scale longitudinal survey studies would be useful.

Questions of generalizability also arise in our second study, which had a small sample size and primarily included science program participants from only one university. Although the sample size was small, we were able to include almost all of the students who participated in science support programs at that university during the 2006-2007 academic year. Assuming that the characteristics of participants do not change dramatically from year to year, we feel confident 
generalizing to the broader population of program participants at this one university. The programs themselves were diverse, however, so the student participants had a wide variety of experiences in the programs that might have been associated with some of our study variables. Additionally, the data reported in this article are over 10 years old, so it is possible some of the observations would not be replicated today. That said, we have no strong reason to believe that the psychological mechanisms observed in these studies would function differently in a newly collected sample as a function of time. To generalize further, additional studies are necessary and we are actively engaged in conducting those studies. It would be especially illuminating to conduct a prospective study with a large sample size. This would allow for more rigorous tests of the mediational model, including being better able to account for the intercorrelations among the variables in the model.

A fertile area for future research would be the examination of the specific mentor behaviors that result in changes in self-efficacy and identity. Bandura's (1997) description of the four sources of self-efficacy includes mastery experiences, vicarious learning, social persuasion, and emotional reactions. Each and all of these sources provide rich researchable avenues for the specific ways in which mentors effect change in students. Similarly, future work would benefit from examining specific aspects of identity in more depth, such as affirmation and belongingness (Cohen et al., 2006), rather than a general sense of identity as a scientist. Future studies could also explore the ways that mentoring affects how students gain recognition as a scientist, an experience that has been linked to developing an identity as a scientist (Carlone \& Johnson, 2006; Rodriquez, et al., 2017). Another important area for further research is to focus not only on commitment to a science career, but on success in achieving that career. The outcome that we used in our studies was intention to commit to a career in STEM, but we do not know whether or 
not participants actually followed through on their commitment. It would be quite valuable to track students for longer periods of time and examine their actual career and educational pathways. Moreover, research should include additional outcome variables that would vary depending on the participant's place in the pipeline. For example, for undergraduate students, outcome variables could include grades in science courses, performance or knowledge ratings by mentors, and the attainment of bachelor's or advanced degrees in science. For more advanced students, outcome variables could include evaluations by advisors, number of publications, time to degree, and the attainment of postdoctoral or assistant professor positions.

Finally, the present study was limited by two forms of aggregation. First, we examined STEM as a single category. There are, of course, numerous and diverse disciplines within that label that would be important to examine specifically. Second, we examined coarse ethnic/racial groups that corresponded to broad patterns of under-representation in STEM. It would be useful for future research to look at more specific ethnic/racial groups, as well as variations and intersections within groups, not just between groups. Taking these two limitation together, under-representation by gender and ethnicity varies across different STEM domains (Cheryan, 2013; Museus et al., 2011), and thus further analyses disaggregating by discipline and ethnicity simultaneously would be informative.

\section{Conclusion}

In sum, these two studies have demonstrated that science/engineering self-efficacy and identity as a scientist/engineer are important psychological mediators of the effects of science and engineering support experiences on commitment to a career in STEM. Although patterns of results were not dramatically different across gender or ethnic group, further study is warranted to investigate whether these or other mediators play a stronger role for some groups than for 
others. Such study can help researchers and the developers of science support programs to finetune science support offerings, making them as effective as possible for all students. 


\section{References}

Allen, T. D., Day, R., \& Lentz, E. (2005). The role of interpersonal comfort in mentoring relationships. Journal of Career Development, 31, 155-169.

Andersen, L., \& Ward, T. J. (2014). Expectancy-value models for the STEM persistence plans of ninthgrade, high-ability students: A comparison between Black, Hispanic, and White students. Science Education, 98(2), 216-242.

Azmitia, M., Syed, M., \& Radmacher, K. (2008). On the intersection of personal and social identities: Introduction and evidence from a longitudinal study of emerging adults. In M. Azmitia, M. Syed, \& K. Radmacher (Eds.), The intersections of personal and social identities. New Directions for Child and Adolescent Development, 120, 1-16. San Francisco: Jossey-Bass.

Bandura, A. (1986). The explanatory and predictive scope of self-efficacy theory. Journal of Clinical and Social Psychology, 4, 359-373.

Bandura, A. (1997). Self-efficacy: The exercise of control. New York: Freeman.

Baugh, S. G., \& Fagenson-Eland, E. A. (2005). Boundaryless mentoring: An exploratory study of the functions provided by internal versus external organizational mentors. Journal of Applied Social Psychology, 35, 939-955.

Bell, R. L., Blair, L. M., Crawford, B. A., \& Lederman, N. G. (2003). Just do it? Impact of a science apprenticeship program on high school students’ understandings of the nature of science and scientific inquiry. Journal of Research in Science Teaching, 40, 487-509.

Bonous-Hammarth, M. (2000). Pathways to success: Affirming opportunities for science, mathematics, and engineering majors. Journal of Negro Education, 69, 92-111.

Brown, S. D., \& Lent, R. W. (1996). A social cognitive framework for career choice counseling. The Career Development Quarterly, 44, 354-366.

Budassi, J., \& Rafailovich, M. (2018). The effect of university research apprenticeships for high school students on Science, Math, Engineering, and Technology learning and the pursuit of Science, Math, Engineering, and Technology degrees and careers. MRS Communications, 1-11. 
Carlone, H. B. \& Johnson, A. (2007). Understanding the Science Experiences of Successful Women of Color: Science Identity as an Analytic Lens. Journal of Research in Science Teaching, 44(8), 1187-1218.

Chang, M. J., Sharkness, J., Hurtado, S., \& Newman, C. B. (2014). What matters in college for retaining aspiring scientists and engineers from underrepresented racial groups. Journal of Research in Science Teaching, 51(5), 555-580.

Charney, J., Hmelo-Silver, C. E., Sofer, W., Neigeborn, L., Coletta, S., \& Nemeroff, M. (2007).

Cognitive apprenticeship in science through immersion in laboratory practices. International Journal of Science Education, 29, 195-213.

Chemers, M. M., Hu, L., \& Garcia, B. F. (2001). Academic self-efficacy and first-year college student performance and adjustment. Journal of Educational Psychology, 93, 55-64.

Chemers, M. M., Watson, C. B., \& May, S. T. (2000). Dispositional affect and leadership effectiveness: A comparison of self-esteem, optimism, and efficacy. Personality and Social Psychology Bulletin, 26, 267-277.

Chemers, M. M., Zurbriggen, E., Syed, M., Goza, B. K., \& Bearman, S. (2011). The role of efficacy and identity in science career commitment among underrepresented minority students. Journal of Social Issues, 67(3), 469-491.

Cheryan, S., Ziegler, S. A., Montoya, A. K., \& Jiang, L. (2017). Why are some STEM fields more gender balanced than others?. Psychological Bulletin, 143(1), 1-35.

Cheung, G. W. \& Rensvold, R. B. (2002). Evaluating goodness-of-fit indexes for testing measurement invariance. Structural Equation Modeling, 9(2): 233-255

Chinn, C. A., \& Malhotra, B. A. (2002). Epistemologically authentic inquiry in schools: A theoretical framework for evaluating inquiry tasks. Science Education, 86, 175-218; DOI 10.1002/sce.10001.

Cohen, G. L., Garcia, J., Apfel, N., \& Master, A. (2006). Reducing the racial achievement gap: A socialpsychological intervention. Science, 313(5791), 1307-1310.

Cole, E. R. (2009). Intersectionality and research in psychology. American Psychologist, 64(3), 170-180. 
Cook, C., Heath, F., \& Thompson, R. L. (2000). A meta-analysis of response rates in web- or internetbased surveys. Educational and Psychological Measurement, 60, 821-836.

Cooper, C. R., Chavira, G., \& Mena, D. D. (2005). From pipelines to partnerships: A synthesis of research on how diverse families, schools, and communities support children's pathways through school. Journal of Education for Students Placed at Risk, 10(4), 407-430.

Dovidio, J. F., Gaertner, S. L., Niemann, Y. F., \& Snider, K. (2001). Racial, ethnic, and cultural differences in responding to distinctiveness and discrimination on campus: Stigma and common group identity. Journal of Social Issues, 57, 167-188.

Dreher, G. F., \& Ash, R. (1990). A comparative study of mentoring among men and women in managerial, professional and technical positions. Journal of Applied Psychology, 75, 539-546.

DuBois, D. L., \& Silverthorn, N. (2005). Characteristics of natural mentoring relationships and adolescent adjustment: Evidence from a national study. The Journal of Primary Prevention, 26(2), 69-92.

Eccles, J. S. (2009). Who am I and what am I going to do with my life? Personal and collective identities as motivators of action. Educational Psychologist, 44, 78-89.

Eccles, J. S., \& Barber, B. L. (1999). Student council, volunteering, basketball, marching band: What kind of extracurricular involvement matters? Journal of Adolescent Research, 14, 10-43.

Erikson, E. E. (1968). Identity: Youth and crisis. New York: Norton.

Foertsch, J., Alexander, B. B., \& Penberthy, D. (2000). Summer research opportunity programs (SROPs) for minority undergraduates. A longitudinal study of program outcomes 1986-1996. Council for Undergraduate Research Quarterly, 20, 114-119.

Fouad, N. A., Hackett, G., Smith, P.L., Kantamneni, N., Fitzpatrick, M.E., Haag, S., Spencer, D. (2010). Barriers and supports for continuing in mathematics and science: Gender and educational level differences Journal of Vocational Behavior, 77, 361-273. 
Fritz, M. S., MacKinnon, D. P., Williams, J., Goldberg, L., Moe, E. L., \& Elliot, D. L. (2005). Analysis of baseline by treatment interactions in a drug prevention and health promotion program for high school male athletes. Addictive Behaviors, 30, 1001-1005.

Fullilove, R., \& Triesman, P. U. (1990). Mathematics achievement among African American undergradutes at the University of California, Berkeley: An evaluation of the Mathematics Workshop Program. Journal of Negro Education, 59, 463-478.

Gándara, P.\& Maxwell-Jolly, J. (1999). Priming the Pump: Strategies for Increasing the Achievement of Underrepresented Minority Undergraduates. New York: The College Board Publications.

Haeger, H., \& Fresquez, C. (2016). Mentoring for inclusion: the impact of mentoring on undergraduate researchers in the sciences. CBE—Life Sciences Education, 15(3), ar36.

Hausmann, L. R. M., Schofield, J. W., \& Woods, R. L. (2007). Sense of belonging as a predictor of intentions to persist among African American and White first-year college students. Research in Higher Education, 48, 803-839.

Hazari, Z., Sonnert, G., Sadler, P. M., Shanahan, M. (2010). Connecting high school physics experiences, outcome expectations, physics identity, and physics career choice: A gender study. Journal of Research in Science Teaching, 64, 978-1003.

Higher Education Research Institute (January 2010). Degrees of Success: Bachelor's degree completion rates among initial STEM majors. Los Angeles, CA: Higher Education Research Institute.

Honicke, T., \& Broadbent, J. (2016). The influence of academic self-efficacy on academic performance: A systematic review. Educational Research Review, 17, 63-84.

Hrabowski III, F. A. (2018). Broadening Participation in American Higher Education-A Special Focus on the Underrepresentation of African Americans in STEM Disciplines. The Journal of Negro Education, 87(2), 99-109.

Hu, L., \& Bentler, P. M. (1995). Evaluating model fit. In R. H. Hoyle (Ed.), Structural equation modeling: Issues, concepts, and applications (pp. 76-99). Newbury Park, CA: Sage. 
Hurd, N. M., Tan, J. S., \& Loeb, E. L. (2016). Natural mentoring relationships and the adjustment to college among underrepresented students. American Journal of Community Psychology, 57(3-4), 330-341.

Hurtado, S., \& Ponjuan, L. (2005). Latino educational outcomes and the campus climate. Journal of Hispanic Higher Education, 4, 235-251.

Jones, M. T., Barlow, A. E., \& Villarejo, M. (2010). Importance of undergraduate research for minority persistence and achievement in biology. The Journal of Higher Education, 81(1), 82-115.

Kardash, C. M. (2000). Evaluation of an undergraduate research experience: Perceptions of undergraduate interns and their faculty mentors. Journal of Educational Psychology, 92, 191201.

Kline, R. B. (2016). Principles and practices of structural equation modeling $\left(4^{\text {th }}\right.$ Ed.). New York: Guilford Press.

Kudish, P., Shores, R., McClung, A., Smulyan, L., Vallen, E. A., \& Siwicki, K. K. (2016). Active learning outside the classroom: implementation and outcomes of peer-led team-learning workshops in introductory biology. CBE—Life Sciences Education, 15(3), ar31.

Lee, K., Alston, A. T., \& Kahn, K. B. (2015). Identity threat in the classroom: Review of women’s motivational experiences in the sciences. Translational Issues in Psychological Science, 1, 321330.

Lent, R. W., Brown, S. D., \& Hackett, G. (1994). Toward a unifying social cognitive theory of career and academic interest, choice, and performance. Journal of Vocational Behavior, 45, 79-122.

Lent, R. W., Brown, S. D. \& Larkin, K.C. (1986). Self-efficacy in the prediction of academic performance and perceived career options. Journal of Counseling Psychology, 33, 265-269.

Lewis, K. L., Stout, J. G., Finkelstein, N. D., Pollock, S. J., Miyake, A., Cohen, G. L., \& Ito, T. A. (2017). Fitting in to move forward: Belonging, gender, and persistence in the physical sciences, technology, engineering, and mathematics (pSTEM). Psychology of Women Quarterly, 41, 420436. 
Little, T. D., Cunningham, W. A., Shahar, G., \& Widaman, K. F. (2002). To parcel or not to parcel: Exploring the question, weighing the merits. Structural Equation Modeling, 9, 151-173

Luhtanen, R., \& Crocker, J. (1992). A collective self-esteem scale: Self-evaluation of one’s social identity. Personality and Social Psychology Bulletin, 18, 302-318.

Manzano-Sanchez, H., Outley, C., Gonzalez, J. E., \& Matarrita-Cascante, D. (2018). The influence of self-efficacy beliefs in the academic performance of Latina/o students in the United States: A systematic literature review. Hispanic Journal of Behavioral Sciences, 402, 176-209.

Maton, K. I., Beason, T. S., Godsay, S., Sto. Domingo, M. R., Bailey, T. C., Sun, S., \& Hrabowski III, F. A. (2016). Outcomes and processes in the Meyerhoff scholars program: STEM PhD completion, sense of community, perceived program benefit, science identity, and research selfefficacy. CBE-Life Sciences Education, 15(3), ar48.

McDevitt, A. L., Patel, M. V., Rose, B., \& Ellison, A. M. (2016). Insights into student gains from undergraduate research using pre-and post-assessments. BioScience, biw141.

Multon, K. D., Brown, S. D., \& Lent, R. W. (1991). Relation of self-efficacy beliefs to academic outcomes: A meta-analytic investigation. Journal of Counseling Psychology, 38, 30-38.

Museus, S. D., Palmer, R. T., Davis, R. J., \& Maramba, D. (Eds.). (2011). Racial and Ethnic Minority Student Success in STEM Education: ASHE Higher Education Report, Volume 36, Number 6. John Wiley \& Sons.

Nolan, J. M., Hanley, B. G., DiVietri, T. P., \& Harvey, N. A. (2018). She who teaches learns: Performance benefits of a jigsaw activity in a college classroom. Scholarship of Teaching and Learning in Psychology, 4(2), 93.

Ortiz-Walters, R., \& Gilson, L. L. (2005). Mentoring in academia: An examination of the experiences of protégés of color. Journal of Vocational Behavior, 67, 459-475.

Osborne, J. W., \& Walker, C. (2006). Stereotype threat, identification with academics, and withdrawal from school: Why the most successful students of colour might be most likely to withdraw. Educational Psychology, 26, 563-577. 
Parker, P. D., Marsh, H. W., Ciarrochi, J., Marshall, S., \& Abduljabbar, A. S. (2014). Juxtaposing math self-efficacy and self-concept as predictors of long-term achievement outcomes. Educational Psychology, 34(1), 29-48.

Richardson, M., Abraham, C., \& Bond, R. (2012). Psychological correlates of university students' academic performance: A systematic review and meta-analysis. Psychological Bulletin, 138(2), 353.

Robbins, S. B., Lauver, K., Le, H., Davis, D., Langley, R., \& Carlstrom, A. (2004). Do psychosocial and study skill factors predict college outcomes? A meta-analysis. Psychological Bulletin, 130(2), 261.

Robnett, R. D., Chemers, M. M., \& Zurbriggen, E. L. (2015). Longitudinal associations among undergraduates' research experience, self-efficacy, and identity. Journal of Research in Science Teaching, 52, 847-867.

Robnett, R. D., Nelson, P. A., Zurbriggen, E. L., Crosby, F. J., \& Chemers, M. M. (2018). The form and function of STEM research, entoring: A mixed-methods analysis focusing on ethnically diverse undergraduates and their mentors. Emerging Adulthood.

Robnett, R. D., Ruvalcaba, O., Syed, M., \& Chemers, M. M. (in press). Turning points in the pursuit of STEM careers: A mixed-methods analysis focusing on women of color. To appear in B. Polnick, B. Irby, \& J. Ballenger. (Eds.), Girls and women of color in STEM: Navigating the double bind. Charlotte, NC: Information Age Publishing Inc.

Robnett, R. D., \& Thoman, S. E. (2017). STEM success expectancies and achievement among women in STEM majors. Journal of Applied Developmental Psychology, 52, 91-100.

Rochin, R. I., \& Mello, S. F. (2007). Latinos in science. Journal of Hispanic Higher Education,6, 305355.

Rodriguez, S., Cunningham, K., \& Jordan, A. (2017). STEM Identity Development for Latinas: The Role of Self- and Outside Recognition. Journal of Hispanic Higher Education. Online first. doi: $10.1177 / 1538192717739958$ 
Ryder, J., \& Leach, J. (1999). University science students’ experiences of investigative project work and their images of science. International Journal of Science Education, 21, 945-956.

Sadler, T. d., Burgin, S., McKinney, L., \& Punjuan, L. (2010). Learning science through research apprenticeships: A critical review of the literature. Journal of Research in Science Teaching, 47, 235-256.

Sellers, R. M., Smith, M. A., Shelton, J. N., Rowley, S. A. J., \& Chavous, T. M. (1998). Multidimensional model of racial identity: A reconceptualization of African American racial identity. Personality and Social Psychology Review, 2, 18-39.

Seymour, E., Hunter, A., Laursen, s. A., \& Deantoni, T. (2004). Establishing the benefits of research experiences for undergraduates in the sciences: First findings from a three-year study. Science Education, 88, 493-534.

Stole-McAllister, K., Sto. Domingo, M. R., \& Carrillo, A. (2011). The Meyerhoff Way: How the Meyerhoff Scholarship Program helps Black students succeed in the sciences. Journal of Science Education and Technology, 20, 5-16.

Syed, M., Azmitia, M., \& Cooper, C. R. (2011). Identity and academic success among under-represented ethnic minorities: An interdisciplinary review and integration. Journal of Social Issues, 67(3), 442-468.

Syed, M., \& Chemers, M. M. (2011). Ethnic minorities and women in STEM: Casting a wide net to address a persistent social problem. Journal of Social Issues, 67(3), 435-441.

Tenenbaum, H. R., Crosby, F. J., \& Gliner, M. D. (2001). Mentoring relationships in graduate school. Journal of Vocational Behavior, 59, 326-341.

Umaña-Taylor, A. J., Quintana, S. M., Lee, R. M., Cross, W. E., Rivas-Drake, D., Schwartz, S. J., Syed, M., Yip, T., Seaton, E., \& Ethnic/Racial Identity Study Group. (2014). Ethnic and racial identity revisited: An integrated conceptualization. Child Development, 85, 21-39.

Walton, G. M., \& Cohen, G. L. (2007). A question of belonging: Race, social fit, and achievement. Journal of Personality and Social Psychology, 92, 82-96. 
Watson, C. B., Chemers, M. M., \& Presier, N. (2001). Collective efficacy: A multilevel analysis. Personality and Social Psychology Bulletin, 27, 1057-1068.

Wuchty, S., Jones, B. F., \& Uzzi, B. (2007). The increasing dominance of teams in production of knowledge. Science, 316, 1036-1039.

Zimmerman, B. J. (1989). A social cognitive view of self-regulated academic learning. Journal of Educational Psychology, 81, 329-339.

Zimmerman, B. J. (1995). Self-efficacy and educational development. In Bandura, A. (Ed.) Self-efficacy in changing societies (pp. 202-231). Cambridge, UK: Cambridge University Press.

Zimmerman, B. J. \& Ringle, J. (1981). Effects of model persistence and statements of confidence on children’s self-efficacy and problem solving. Journal of Educational Psychology, 73, 485-493.

Zimmerman, B. J. \& D. H. Schunk (Eds.). (1989). Self-regulated learning and academic achievement: Theory, research, and practice. New York: Springer-Verlag. 
Table 1

Demographics of STEM Majors 1999/2000 through 2004-05 and Study 1 Participants

\begin{tabular}{lcccc}
\hline \multirow{2}{*}{ Ethnic Background } & \multicolumn{2}{c}{ STEM Majors } & \multicolumn{2}{c}{ Study 1 Participants } \\
\cline { 2 - 5 } & $\mathrm{n}$ & $\%$ & $\mathrm{n}$ & $\%$ \\
\hline Women & 3393 & 40.98 & 281 & 55.98 \\
\hline Chicano/Latino & 1,033 & 12.48 & 120 & 23.90 \\
African American & 227 & 2.74 & 41 & 8.17 \\
Native American & 67 & 0.81 & 9 & 1.80 \\
$\quad$ Underrepresented Minority Subtotal & 1,327 & 16.03 & 170 & 33.86 \\
White & 4,063 & 49.08 & 199 & 39.64 \\
Asian & 1,855 & 22.40 & 114 & 22.71 \\
Other/Unknown & 1,034 & 12.49 & 19 & 3.78 \\
\hline Total & 8,279 & 100.00 & 502 & 100.00 \\
\hline
\end{tabular}


Table 2

Fit Indices for Confirmatory Factor Analyses

\begin{tabular}{|c|c|c|c|c|c|}
\hline & $\begin{array}{l}\text { Overall } \\
\text { Model }\end{array}$ & $\begin{array}{c}\text { Ethnicity } \\
\text { Model }\end{array}$ & $\begin{array}{l}\text { Gender } \\
\text { Model }\end{array}$ & $\begin{array}{l}\text { Science vs. } \\
\text { Engineering } \\
\text { Model }\end{array}$ & $\begin{array}{c}\text { Program vs. } \\
\text { No Program } \\
\text { Model }\end{array}$ \\
\hline \multicolumn{6}{|c|}{$\begin{array}{l}\text { Research experience, } \\
\text { academic support, and } \\
\text { community support }\end{array}$} \\
\hline CFI & .97 & .97 & .97 & .97 & .97 \\
\hline TLI & .95 & .96 & .96 & .96 & .95 \\
\hline SRMR & .05 & .05 & .05 & .05 & .06 \\
\hline RMSEA & .10 & .09 & .09 & .09 & .10 \\
\hline \multicolumn{6}{|c|}{$\begin{array}{l}\text { Instrumental mentoring } \\
\text { and socioemotional } \\
\text { mentoring }\end{array}$} \\
\hline CFI & .99 & .98 & .99 & .99 & .99 \\
\hline TLI & .99 & .97 & .99 & .99 & .99 \\
\hline SRMR & .04 & .05 & .03 & .03 & .04 \\
\hline RMSEA & .06 & .11 & .07 & .07 & .06 \\
\hline \multicolumn{6}{|c|}{$\begin{array}{l}\text { Science self-efficacy and } \\
\text { teamwork/leadership self- } \\
\text { efficacy }\end{array}$} \\
\hline CFI & .99 & .99 & .99 & .99 & 1.0 \\
\hline TLI & .99 & .99 & .99 & .99 & 1.0 \\
\hline SRMR & .03 & .04 & .04 & .05 & .04 \\
\hline RMSEA & .03 & .06 & .05 & .05 & .00 \\
\hline
\end{tabular}


Identity as a scientist and commitment to a science career

\begin{tabular}{llllll} 
CFI & .99 & .99 & .99 & .99 & .99 \\
TLI & .98 & .99 & .99 & .98 & .99 \\
SRMR & .02 & .04 & .03 & .03 & .02 \\
RMSEA & .07 & .05 & .05 & .08 & .05 \\
\hline
\end{tabular}


Table 3

Means, Standard Deviations, and Bivariate Correlations for Underrepresented Minority (URM) Students in Study 1

\begin{tabular}{|c|c|c|c|c|c|c|c|c|c|c|c|}
\hline & $M$ & $S D$ & 1 & 2 & 3 & 4 & 5 & 6 & 7 & 8 & 9 \\
\hline 1. Research Experience & 2.43 & 1.18 & -- & & & & & & & & \\
\hline 2. Instrumental Mentoring & 3.22 & 1.15 & .69 & -- & & & & & & & \\
\hline $\begin{array}{l}\text { 3. Socioemotional } \\
\text { Mentoring }\end{array}$ & 3.23 & 1.01 & .49 & .65 & -- & & & & & & \\
\hline 4. Community Involvement & 2.81 & 1.07 & .57 & .54 & .48 & -- & & & & & \\
\hline 5. Academic Support & 2.60 & 1.01 & .49 & .49 & .51 & .52 & -- & & & & \\
\hline 6. Financial Support & 3.51 & 1.51 & .55 & .34 & .33 & .50 & .43 & -- & & & \\
\hline 7. Science Self-efficacy & 3.75 & 0.89 & .55 & .41 & .37 & .47 & .24 & .38 & -- & & \\
\hline $\begin{array}{l}\text { 8. Teamwork \& Leadership } \\
\text { Self-efficacy }\end{array}$ & 4.21 & 0.58 & .37 & .28 & .30 & .41 & .26 & .27 & .49 & -- & \\
\hline 9. Identity as a Scientist & 3.40 & 0.70 & .41 & .27 & .23 & .37 & .24 & .30 & .49 & .45 & -- \\
\hline $\begin{array}{l}\text { 10. Commitment to a } \\
\text { Science Career }\end{array}$ & 3.70 & 0.88 & .48 & .36 & .30 & .36 & .22 & .32 & .60 & .36 & .58 \\
\hline
\end{tabular}

Note. All ps $<.01$ 
Table 4

Means, Standard Deviations, and Bivariate Correlations for White Students in Study 1

\begin{tabular}{|c|c|c|c|c|c|c|c|c|c|c|c|}
\hline & $M$ & $S D$ & 1 & 2 & 3 & 4 & 5 & 6 & 7 & 8 & 9 \\
\hline 1. Research Experience & 2.28 & 1.04 & -- & & & & & & & & \\
\hline 2. Instrumental Mentoring & 2.78 & 1.14 & .79 & -- & & & & & & & \\
\hline $\begin{array}{l}\text { 3. Socioemotional } \\
\text { Mentoring }\end{array}$ & 2.91 & 0.97 & .49 & .64 & -- & & & & & & \\
\hline 4. Community Involvement & 2.59 & 0.97 & .41 & .50 & .44 & -- & & & & & \\
\hline 5. Academic Support & 2.06 & 0.72 & .31 & .32 & .43 & .48 & -- & & & & \\
\hline 6. Financial Support & 2.63 & 1.54 & .32 & .35 & .29 & .26 & .26 & -- & & & \\
\hline 7. Science Self-efficacy & 3.68 & 0.86 & .52 & .44 & .30 & .28 & .18 & .21 & -- & & \\
\hline $\begin{array}{l}\text { 8. Teamwork \& Leadership } \\
\text { Self-efficacy }\end{array}$ & 4.19 & 0.55 & .28 & .26 & .20 & .35 & .24 & $.07^{\ddagger}$ & .22 & -- & \\
\hline 9. Identity as a Scientist & 3.31 & 0.76 & .38 & .37 & .26 & .36 & .18 & $.12^{\ddagger}$ & .30 & .19 & -- \\
\hline $\begin{array}{l}\text { 10. Commitment to a } \\
\text { Science Career }\end{array}$ & 3.58 & 0.97 & .52 & .51 & .34 & .32 & .17 & .17 & .49 & .26 & .70 \\
\hline
\end{tabular}

Note. All ps $<.05$, except ${ }^{\ddagger}$ 
Table 5

Fit Statistics for all Path Models in Study 1

\begin{tabular}{|c|c|c|c|c|c|c|c|c|}
\hline & $\begin{array}{l}\text { Model A } \\
\text { Full }\end{array}$ & $\begin{array}{l}\text { Model B } \\
\text { Reduced } \\
\quad \text { Full }\end{array}$ & $\begin{array}{l}\text { Model C } \\
\text { Fully } \\
\text { Mediated }\end{array}$ & $\begin{array}{l}\text { Model D } \\
\text { Partially } \\
\text { Mediated }\end{array}$ & $\begin{array}{l}\text { Model E } \\
\text { Trimmed } \\
\text { Partially } \\
\text { Mediated }\end{array}$ & $\begin{array}{c}\text { Model F } \\
\text { Fully } \\
\text { Constrained } \\
\text { Across } \\
\text { Ethnicity } \\
\end{array}$ & $\begin{array}{c}\text { Model G } \\
\text { Unconstrained } \\
\text { Across } \\
\text { Ethnicity }\end{array}$ & $\begin{array}{l}\text { Model H } \\
\text { Final }\end{array}$ \\
\hline$\chi^{2}$ & 538.43 & 278.16 & 293.64 & 281.08 & 281.24 & 499.79 & 471.83 & 452.78 \\
\hline df & 258 & 105 & 108 & 107 & 109 & 250 & 240 & 238 \\
\hline$p$ & $<.001$ & $<.001$ & $<.001$ & $<.001$ & $<.001$ & $<.001$ & $<.001$ & $<.001$ \\
\hline CFI & .97 & .97 & .97 & .97 & .97 & .96 & .96 & .96 \\
\hline TLI & .96 & .96 & .96 & .96 & .96 & .95 & .96 & .96 \\
\hline SRMR & .04 & .05 & .05 & .05 & .05 & .07 & .06 & .05 \\
\hline $\begin{array}{l}\text { RMSEA } \\
(90 \% \text { C.I.) }\end{array}$ & $\begin{array}{c}.05(.05 \\
.06)\end{array}$ & $\begin{array}{c}.07(.06 \\
.08)\end{array}$ & $\begin{array}{c}.07(.06 \\
.08)\end{array}$ & $\begin{array}{c}.07(.06 \\
.08)\end{array}$ & $\begin{array}{c}.07(.06 \\
.08)\end{array}$ & $.07(.06, .08)$ & $.07(.06, .08)$ & $\begin{array}{c}.07(.06 \\
.08)\end{array}$ \\
\hline ssBIC & 17875.05 & 11921.22 & 11928.48 & 11918.67 & 11913.35 & 11927.88 & 11927.31 & 11913.73 \\
\hline
\end{tabular}


Table 6

Means, Standard Deviations, and Bivariate Correlations for Study 2

\begin{tabular}{|c|c|c|c|c|c|c|c|c|c|c|c|c|}
\hline & $\begin{array}{l}\text { Research } \\
\text { Exper. }\end{array}$ & $\begin{array}{l}\text { Aca. } \\
\text { Supp. }\end{array}$ & $\begin{array}{l}\text { Comm. } \\
\text { Involve }\end{array}$ & $\begin{array}{l}\text { Fin. } \\
\text { Supp. }\end{array}$ & $\begin{array}{l}\text { Instr. } \\
\text { Ment }\end{array}$ & $\begin{array}{c}\text { Socio- } \\
\text { emo } \\
\text { Ment }\end{array}$ & $\begin{array}{l}\text { Science } \\
\text { Efficacy }\end{array}$ & $\begin{array}{l}\text { Leader } \\
\text { Efficacy }\end{array}$ & Identity & Commit & $\begin{array}{c}\text { Mean } \\
\text { Time } \\
2 \\
\end{array}$ & $\begin{array}{c}\text { SD } \\
\text { Time } \\
2 \\
\end{array}$ \\
\hline Research Experience & .40 & .22 & .60 & .04 & .63 & .33 & .48 & .23 & .38 & .32 & 3.43 & 0.71 \\
\hline Academic Support & .09 & .66 & .56 & .09 & .39 & .56 & .08 & .20 & .04 & -.07 & 2.78 & 0.90 \\
\hline $\begin{array}{l}\text { Community } \\
\text { Involvement }\end{array}$ & .47 & .41 & .57 & .08 & .53 & .39 & .31 & .26 & .29 & .29 & 2.94 & 0.97 \\
\hline Financial Support & .15 & .12 & .26 & .62 & .18 & .09 & .12 & .20 & .15 & .17 & 3.11 & 1.34 \\
\hline Inst. Mentoring & .57 & .37 & .32 & .13 & .44 & .63 & .60 & .37 & .29 & .33 & 3.69 & 0.70 \\
\hline Socio Mentoring & .24 & .38 & .16 & .14 & .65 & .58 & .34 & .38 & .14 & .08 & 3.72 & 0.80 \\
\hline Science Self Efficacy & .46 & .01 & .25 & -.09 & .42 & .20 & .46 & .48 & .24 & .25 & 3.79 & 0.67 \\
\hline Team \& Leader SE & .06 & .30 & .29 & .08 & .19 & .14 & .29 & .60 & .38 & .29 & 4.27 & 0.60 \\
\hline Identity as a Scientist & .23 & .06 & .22 & .05 & .22 & .03 & .32 & .12 & .64 & .62 & 3.99 & 0.79 \\
\hline Commitment & .26 & -.13 & .16 & .10 & .19 & .16 & .24 & .21 & .48 & .61 & 4.45 & 0.58 \\
\hline Mean Time 1 & 2.34 & 2.46 & 2.56 & 2.96 & 3.23 & 3.52 & 3.31 & 4.30 & 3.83 & 4.51 & & \\
\hline SD Time 1 & 0.95 & 0.83 & 0.96 & 1.53 & 0.89 & 0.75 & 0.76 & 0.52 & 0.65 & 0.53 & & \\
\hline
\end{tabular}

Note. Correlations below the diagonal are for Time 1, above the diagonal for Time 2. Shaded values on the diagonal are the Time1/Time2 correlations.

$r s>.23, p<.05$

$r \mathrm{~s}>.31, p<.01$ 
Table 7

Hierarchical Regression Analyses of Change in Program Components and Psychological Mediators in Study 2

\begin{tabular}{|c|c|c|c|c|c|c|c|c|c|c|c|c|}
\hline & \multicolumn{3}{|c|}{$\begin{array}{c}\text { Time } 2 \\
\text { Science/Engineering } \\
\text { Self-Efficacy }\end{array}$} & \multicolumn{3}{|c|}{$\begin{array}{c}\text { Time } 2 \\
\text { Team/Lead Self- } \\
\text { Efficacy }\end{array}$} & \multicolumn{3}{|c|}{$\begin{array}{c}\text { Time } 2 \\
\text { Identity as a } \\
\text { Scientist/Engineer }\end{array}$} & \multicolumn{3}{|c|}{$\begin{array}{c}\text { Time } 2 \\
\text { Commitment }\end{array}$} \\
\hline & $R^{2}$ & $b^{*}$ & $s r^{2}$ & $R^{2}$ & $b^{*}$ & $s r^{2}$ & $R^{2}$ & $b^{*}$ & $s r^{2}$ & $R^{2}$ & $b^{*}$ & $s r^{2}$ \\
\hline Step 1: Initial Level & .18 & $.43^{* *}$ & .43 & .32 & $.57 * * *$ & .57 & .41 & $.64 * * *$ & .64 & .36 & $.60 * * *$ & .60 \\
\hline Step 2: Program Components & .47 & & & .38 & & & .46 & & & & & \\
\hline Initial Level & & $.71^{* * *}$ & .59 & & $.57^{* * *}$ & .52 & & $.72 * * *$ & .66 & & & \\
\hline$\Delta$ Research Experience & & -.06 & -.04 & & -.09 & -.06 & & -.02 & -.01 & & & \\
\hline$\Delta$ Inst. Mentoring & & .17 & .12 & & -.05 & -.04 & & .10 & .07 & & & \\
\hline$\Delta$ Socio Mentoring & & .17 & .15 & & .22 & .18 & & .07 & .06 & & & \\
\hline$\Delta$ Community Involvement & & $.52 * *$ & .36 & & .09 & .06 & & .02 & .01 & & & \\
\hline$\Delta$ Academic Support & & -.06 & -.05 & & .13 & .10 & & .16 & .13 & & & \\
\hline$\Delta$ Financial Support & & -.17 & -.15 & & -.09 & -.08 & & -.18 & -.16 & & & \\
\hline Step 2: Psychological Mediators & & & & & & & & & & .52 & & \\
\hline Initial Level & & & & & & & & & & & $.58 * * *$ & .58 \\
\hline$\Delta$ Science/Engineering SE & & & & & & & & & & & .08 & .08 \\
\hline$\Delta$ Team \& Leader SE & & & & & & & & & & & .15 & .13 \\
\hline$\Delta$ Identity as a Scientist/Engineer & & & & & & & & & & & $.28 * *$ & .25 \\
\hline
\end{tabular}

Note. $\Delta=$ difference score between Time 1 and Time 2. The Initial Level variable is different for each regression, and represents the Time 1 value for the dependent variable (e.g., for the first regression, Initial Level is Time 1 science/engineering self-efficacy)

${ }^{* *} p<.01, * * * p<.001$ 


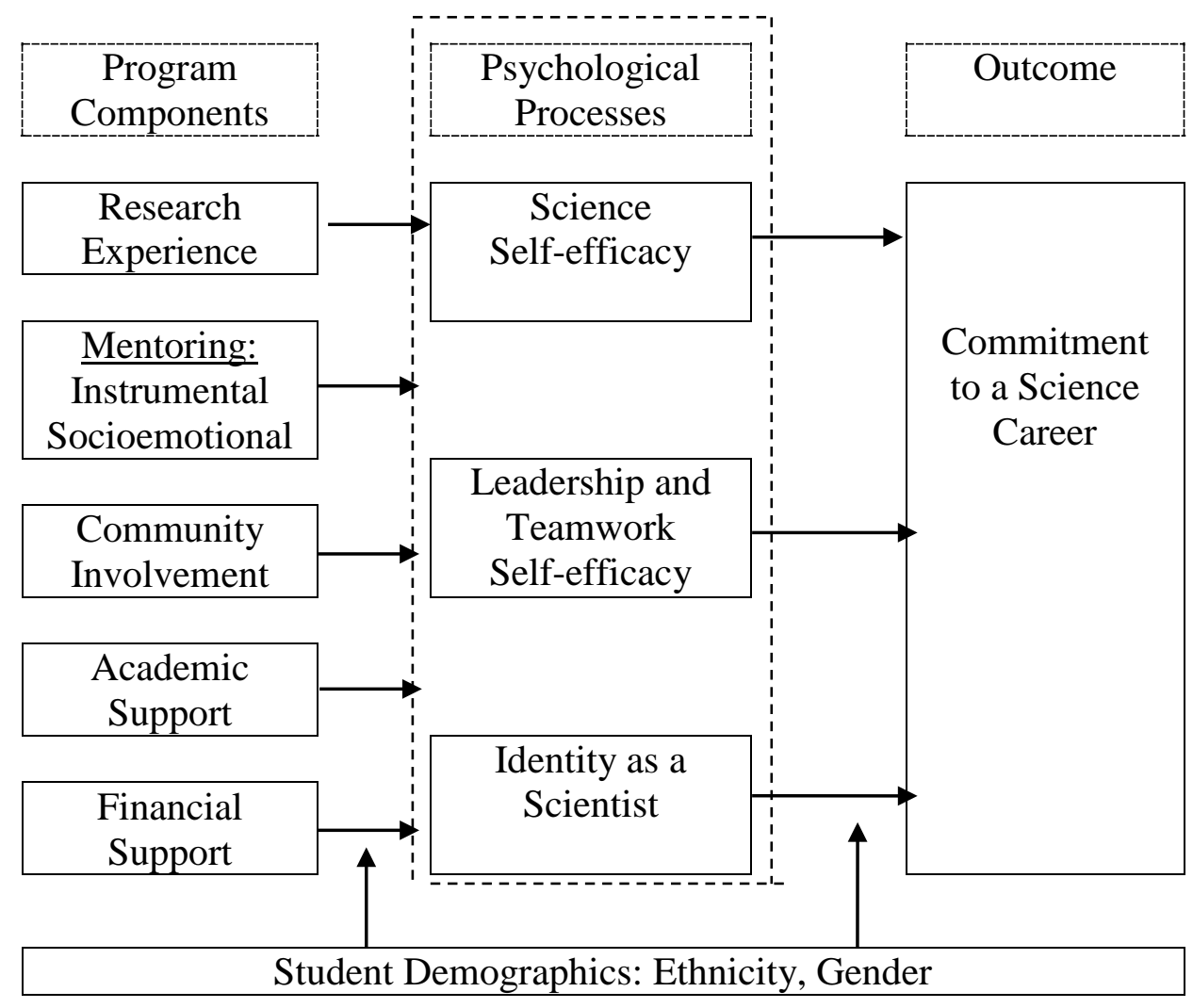

Figure 1. Mediational Model of Research Experiences (MMRE) Tested in Study 1. 


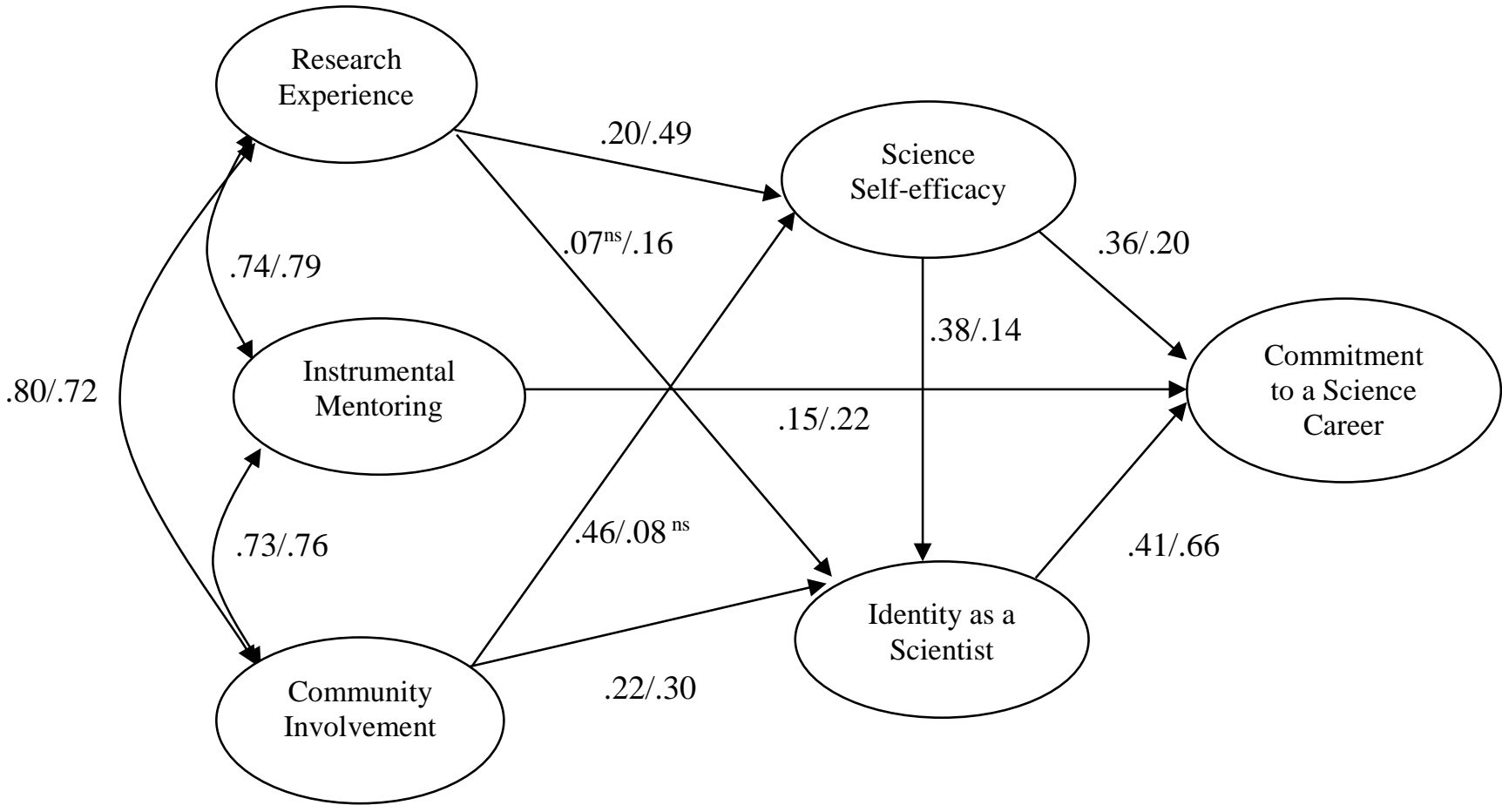

Model Fit: $\chi^{2}(238)=152.78, p<.001, \mathrm{CFI}=.96, \mathrm{TLI}=.96, \mathrm{SRMR}=.05$, RMSEA $=.07(.06, .08)$

Figure 2. Final multi-group SEM model for Study 1. Measurement model not shown for parsimony. Standardized coefficients for URM students are on the left, White students on the right. All paths significant at $p<.05$ unless otherwise noted. 


\section{Biographical Sketches}

Moin Syed is an Associate Professor of Psychology at the University of Minnesota, Twin Cities. His research is broadly concerned with identity and personality development among ethnically and culturally-diverse adolescents and emerging adults. He is co-Editor of the Oxford Handbook of Identity Development and the Editor of Emerging Adulthood, the official journal of the Society for the Study of Emerging Adulthood.

Eileen L. Zurbriggen is a Professor of Psychology at the University of California, Santa Cruz where she is also affiliated with the Department of Feminist Studies. Her research focuses on gender, power, and oppression, especially among adolescent populations. She is a fellow of the American Psychological Association and the Association for Psychological Science.

Martin M. Chemers received a PhD in Social Psychology from the University of Illinois, Urbana. He is presently Professor Emeritus and Research Professor of Psychology at the University of California, Santa Cruz. His current research is supported by the National Institutes of Health and is focused on understanding and developing the individual and institutional changes needed to increase the number of underrepresented minorities in STEM education and careers.

Barbara K. Goza completed her PhD in social/organizational psychology at the University of Utah. For over 30 years, she has specialized in program evaluation of educational and mental health programs. She has directed and taught program evaluation and applied research at the University of Utah, California State Polytechnic University Pomona, and the University of California, Santa Cruz.

Steve Bearman received his PhD in social psychology from the University of California, Santa Cruz. His work integrates the perspective that people are not self-contained entities, but rather are distributed across networks of interactions, with research on interventions to diminish racism and other forms of oppression.

Faye J. Crosby is Distinguished Professor of Psychology at the University of California, Santa Cruz. A long-time SPSSI member, she was honored to serve as its President in 1991-1992. Crosby has published nearly 200 scholarly works, including 14 books, mostly on topics concerning discrimination and remedies to discrimination. Crosby has been awarded several honors including the Carolyn Wood Sherif award from Division 35 of the American Psychological Association and the Kurt Lewin Award from SPSSI.

Jerome M. Shaw is Associate Professor of Science Education Emeritus at the University of California, Santa Cruz. He has over 40 years experience in education with a focus on understanding and improving science teaching and learning for culturally and linguistically diverse students.

Lisa Hunter is Director of the Institute for Scientist \& Engineer Educators at the University of California, Santa Cruz. Her work focuses on equity, inclusion and diversity in science and engineering. She develops and evaluates programs that span the undergraduate to early career 
professional stages, as well as working with industry scientist and engineers who mentor students engaged in research and design projects in the workplace.

Elizabeth M. Morgan is an Associate Professor of Psychology at Springfield College. Her research generally focuses on sexual identity and romantic relationship development among adolescents and emerging adults. 